\title{
Deletion of Neuronal GLT-1 in Mice Reveals Its Role in Synaptic Glutamate Homeostasis and Mitochondrial Function
}

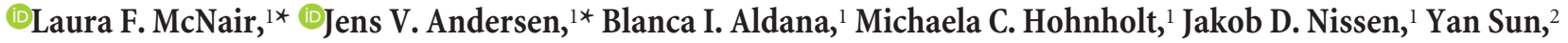 \\ Kathryn D. Fischer, ${ }^{2}$ Ursula Sonnewald, ${ }^{1,3}$ Nils Nyberg, ${ }^{1}$ Sophie C. Webster, ${ }^{2}$ Kush Kapur, ${ }^{2}$ Theresa S. Rimmele, ${ }^{2}$ \\ Ilaria Barone, ${ }^{2}$ Hannah Hawks-Mayer, ${ }^{2}$ Jonathan 0. Lipton, ${ }^{2,4}$ - Nathaniel W. Hodgson, ${ }^{2}$ Takao K. Hensch, ${ }^{2}$ \\ (C) Chiye J. Aoki, ${ }^{5,6}$-Paul A. Rosenberg, ${ }^{2,7 \dagger}$ and $\odot$ Helle S. Waagepetersen ${ }^{1 \dagger}$ \\ ${ }^{1}$ Department of Drug Design and Pharmacology, University of Copenhagen, 2100 Copenhagen, Denmark, ${ }^{2}$ Department of Neurology and the F.M. Kirby \\ Neurobiology Center, Boston Children's Hospital, Boston, Massachusetts 02115, ${ }^{3}$ Department of Neuroscience, Norwegian University of Science and \\ Technology, N-7489 Trondheim, Norway, ${ }^{4}$ Division of Sleep Medicine, Harvard Medical School, Boston, Massachusetts 02115, ${ }^{5}$ Center of Neural Science, \\ New York University, New York, New York 10003, ${ }^{6}$ Neuroscience Institute, New York University Langone Medical Center, New York, New York 10016, \\ and ${ }^{7}$ Program in Neuroscience, Harvard Medical School, Boston, Massachusetts, 02115
}

The glutamate transporter GLT-1 is highly expressed in astrocytes but also in neurons, primarily in axon terminals. We generated a conditional neuronal GLT-1 K0 using synapsin 1-Cre (synGLT-1 K0) to elucidate the metabolic functions of GLT-1 expressed in neurons, here focusing on the cerebral cortex. Both synaptosomal uptake studies and electron microscopic immunocytochemistry demonstrated knockdown of GLT-1 in the cerebral cortex in the synGLT-1 KO mice. Aspartate content was significantly reduced in cerebral cortical extracts as well as synaptosomes from cerebral cortex of synGLT-1 KO compared with control littermates. ${ }^{13} \mathrm{C}$-Labeling of tricarboxylic acid cycle intermediates originating from metabolism of $\left[\mathrm{U}-{ }^{13} \mathrm{C}\right]$-glutamate was significantly reduced in synGLT-1 KO synaptosomes. The decreased aspartate content was due to diminished entry of glutamate into the tricarboxylic acid cycle. Pyruvate recycling, a pathway necessary for full glutamate oxidation, was also decreased. ATP production was significantly increased, despite unaltered oxygen consumption, in isolated mitochondria from the synGLT-1 KO. The density of mitochondria in axon terminals and perisynaptic astrocytes was increased in the synGLT-1 KO. Intramitochondrial cristae density of synGLT-1 KO mice was increased, suggesting increased mitochondrial efficiency, perhaps in compensation for reduced access to glutamate. SynGLT-1 K0 synaptosomes exhibited an elevated oxygen consumption rate when stimulated with veratridine, despite a lower baseline oxygen consumption rate in the presence of glucose. GLT-1 expressed in neurons appears to be required to provide glutamate to synaptic mitochondria and is linked to neuronal energy metabolism and mitochondrial function.

Key words: anaplerosis; aspartate; bioenergetics; Huntington's; neurodegeneration; TCA cycle

Significance Statement

All synaptic transmitters need to be cleared from the extracellular space after release, and transporters are used to clear glutamate released from excitatory synapses. GLT-1 is the major glutamate transporter, and most GLT-1 is expressed in astrocytes. Only $5 \%-10 \%$ is expressed in neurons, primarily in axon terminals. The function of GLT- 1 in axon terminals remains unknown. Here, we used a conditional KO approach to investigate the significance of the expression of GLT-1 in neurons. We found multiple abnormalities of mitochondrial function, suggesting impairment of glutamate utilization by synaptic mitochondria in the neuronal GLT-1 KO. These data suggest that GLT-1 expressed in axon terminals may be important in maintaining energy metabolism and biosynthetic activities mediated by presynaptic mitochondria.

\section{Introduction}

For years only mRNA, but not protein expression, of the glutamate transporter GLT-1 (EAAT2; slc1a2) (Pines et al., 1992)

Received April 5, 2018; revised Feb. 7, 2019; accepted March 10, 2019

Author contributions: L.F.M., J.V.A., B.I.A., M.C.H., J.D.N., Y.S., K.D.F., U.S., N.N., T.S.R., I.B., H.H.-M., J.O.L., N.W.H., C.J.A.,P.A.R., and H.S.W. designed research; L.F.M., J.V.A., B.I.A., M.C.H., J.D.N., Y.S., N.N., S.C.W., T.S.R., I.B., could be detected in neurons (Torp et al., 1994, 1997; Berger and Hediger, 1998), and the existence of any functional glutamate

H.H.-M., N.W.H., and C.J.A. performed research; L.F.M., J.V.A., M.C.H., J.D.N., Y.S., K.D.F., U.S., N.N., S.C.W., K.K. T.S.R., I.B., H.H.-M., J.O.L., N.W.H., C.J.A., P.A.R., and H.S.W. analyzed data; L.F.M. wrote the first draft of the paper; L.F.M., J.V.A., B.I.A., M.C.H., J.D.N., Y.S., K.D.F., U.S., N.N., T.S.R., I.B., H.H.-M., N.W.H., T.K.H., C.J.A., P.A.R., and H.S.W. edited the paper; K.K. and P.A.R. contributed unpublished reagents/analytic tools. 
transporters in axon terminals of excitatory synapses was disputed (Danbolt, 2001; Rimmele and Rosenberg, 2016). GLT-1 was finally shown to be expressed in axon terminals of the hippocampus (Chen et al., 2004; Furness et al., 2008), somatosensory cortex (Melone et al., 2009), and striatum (Petr et al., 2013; for review, see Danbolt et al., 2016; Rimmele and Rosenberg, 2016). An important unanswered question is why neurons express GLT-1. The concept of glutamate homeostasis includes the role of glutamate as a neurotransmitter (Waagepetersen et al., 2005; Sonnewald, 2014; Walls et al., 2015; Borisova, 2016), as a substrate for energy metabolism (McKenna, 2013; Nissen et al., 2015; Hohnholt et al., 2017, 2018), and for biosynthesis (Palm and Thompson, 2017; Venneti and Thompson, 2017; Zhang et al., 2017). It remains to be elucidated whether glutamate transported by GLT-1 into axon terminals plays a role in any of these aspects of glutamate homeostasis.

Neurotransmitter glutamate released from neurons is cleared primarily by GLT-1- and GLAST-mediated uptake in adjacent astrocytes (Rothstein et al., 1996; Danbolt, 2001). Hence, not surprisingly, nonspecific deletion of GLT-1 results in a lethal mouse phenotype (Tanaka et al., 1997). Conditional deletion of GLT-1 in astrocytes has a similar, although less severe, phenotype (Petr et al., 2015). In contrast, selective GLT-1 deletion in neurons does not impact survival (Petr et al., 2015), and neuronal GLT-1 KO mice are behaviorally largely normal on a wide variety of tests, at least up to 1 year of age (Fischer et al., 2018). One possible role of GLT-1 in axon terminals is to maintain the local neurotransmitter glutamate pool by simply providing reuptake of glutamate released from synaptic vesicles. Consistent with this idea, glutamatergic neurotransmission in hippocampal slices and cultured neurons was able to persist for hours in the absence of astrocyte-to-neuron glutamine transfer for repletion of synaptic glutamate (Kam and Nicoll, 2007; Walls et al., 2015; but see Tani et al., 2014). Recent studies have confirmed that GLT-1 expressed in neurons does mediate the uptake of glutamate (Petr et al., 2015), and could therefore contribute to repletion of transmitter glutamate after release.

Alternatively, glutamate taken up via GLT-1 in neurons may be metabolized in mitochondria of axon terminals. If so, glutamate potentially supports metabolic activities to fuel its own release and reuptake as well as biosynthetic activities of presynaptic terminals. This possibility is supported by the extensive oxidative glutamate metabolism observed in glutamatergic neurons in vitro (Sonnewald and McKenna, 2002; Olstad et al., 2007). Moreover, a link between mitochondrial energy metabolism and transportermediated glutamate uptake in astrocytes has recently been suggested (Azarias et al., 2011; McKenna, 2013; Chatton et al., 2016).

This work was supported by the Department of Drug Design and Pharmacology (University of Copenhagen, Denmark) PhD Scholarship to L.F.M. This work was supported in part by Aase og Ejnar Danielsens Fond and National Institutes of Health Grants NS066019, MH104318, MH105846, EY13079, NS007473, EY024481, and HD018655. NMR equipment used in this work was purchased via support from Danish Research Council for Independent Research Nature and Universe Grant 10 - 085264, Apotekerfonden af 1991, and the Danish Agency for Science, Technology and Innovation (National Research Infrastructure funds). The postdoctoral stay of B.I.A. at the Department of Drug Design and Pharmacology is subsidized by the Ministry of Science, Technology and Innovation of Mexico. J.V.A. was supported by the Scholarship of Peter \& Emma Thomsen. T.K.H. was supported by NASA NSCOR and WPI-IRCN (ISPS). We thank Heidi Nielsen for helpful assistance in the laboratory; and Professor Arne Schousboe for constructive feedback on the manuscript.

The authors declare no competing financial interests.

*L.F.M. and J.V.A. contributed equally to this work as co-first authors

${ }^{\dagger}$ P.A.R. and H.S.W. contributed equally to this work as co-senior authors.

Correspondence should be addressed to Helle S. Waagepetersen at helle.waagepetersen@sund.ku.dk or Paul A. Rosenberg at paul.rosenberg@childrens.harvard.edu.

https://doi.org/10.1523/JNEUROSCI.0894-18.2019

Copyright $(2019$ the authors
Finally, it has been proposed that GLT-1 expressed in neurons mediates glutamate release (reverse transport) rather than uptake (Grewer et al., 2008; Borisova, 2016) potentially to regulate glutamate concentrations in the synaptic cleft (Borisova, 2016). However, based on studies of excitatory amino acid transporter 3 (EAAT3, EAAC1; slc1a1) (Kanai and Hediger, 1992; Bjørås et al., 1996), it has been suggested that the glutamate binding sites of the EAATs are optimized for binding of extracellular and not intracellular glutamate, thereby promoting inward transport of glutamate (Watzke and Grewer, 2001; Grewer et al., 2008).

Taking these various lines of evidence together, glutamate transported by GLT-1 expressed in neurons is likely to be either recycled for vesicular release, metabolized at the axon terminal, or both. However, the existence of these two pathways or their significance for the function of the excitatory presynaptic terminal is unknown. In the present study, we investigated the role of neuronal glutamate uptake mediated by GLT-1 in energy metabolism and glutamate homeostasis.

\section{Materials and Methods}

Mice

Male conditional GLT-1 KO mice (Slc1a2 $2^{\text {tm1.1Pros }}$; MGI: 5752263), in which the GLT-1 gene was inactivated in neurons by expression of synapsin-Cre as described previously (GLT-1 ${ }^{\text {flox/flox; synapsin-Cre) }}$ (Petr et al., 2015), and littermate controls with normal GLT-1 function (GLT-1 ${ }^{\text {flox/flox }}$ ) were obtained from the founder colony at Boston Children's Hospital. These are referred to in the current paper as synGLT-1 $\mathrm{KO}$ and controls, respectively.

Mice were housed in humidity- and temperature-controlled facilities, on a normal 12/12 h light/dark cycle (7:00 A.M. to 7:00 P.M. light), with free access to standard chow and water. Animal experiments were conducted at Boston Children's Hospital and University of Copenhagen (Copenhagen, Denmark). All animal experiments at Boston Children's Hospital were performed in accordance with National Institutes of Health guidelines, and were approved by the Boston Children's Hospital Institutional Animal Care and Use Committee. The experiments at the University of Copenhagen were approved by the Danish National Ethics Committee, and were performed according to the European Convention (ETS 123 of 1986). All experiments were reported according to the ARRIVE guidelines.

A total of 84 male mice of different ages were used. A first set of experiments included in vivo assessment of neural metabolism using 33- to 54-week-old mice, and follow-up studies, to confirm and extend findings in the first set of experiments, were performed on two further cohorts of mice $(8-40$ weeks old). The investigators were not aware of the genotype of the animals during the experiments.

\section{In vivo metabolic mapping}

Animal treatment and tissue collection. Seven synGLT-1 KO and 7 control mice (45-54 weeks of age) were injected intraperitoneally with $0.3 \mathrm{M}$ $\left[1-{ }^{13} \mathrm{C}\right]$-glucose $(543 \mathrm{mg} / \mathrm{kg})$ plus $0.6 \mathrm{M}\left[1,2-{ }^{13} \mathrm{C}\right]$-acetate $(504 \mathrm{mg} / \mathrm{kg}$; Cambridge Isotope Laboratories). Fifteen minutes later, the mice were killed by focused beam microwave irradiation to the head (Gerling Applied Engineering Instrument) and decapitated. Cerebral cortex was dissected, and blood was collected and immediately spun to collect plasma, before both were stored at $-80^{\circ} \mathrm{C}$ until subjected to a water/methanolchloroform extraction procedure modified from Le Belle et al. (2002). To each $50 \mu \mathrm{l}$ plasma, $100 \mu \mathrm{l}$ water, $300 \mu \mathrm{l}$ methanol, and $200 \mu \mathrm{l}$ chloroform were added before mixing, centrifugation at $3000 \times g$ at $4^{\circ} \mathrm{C}$ for $15 \mathrm{~min}$ and collection of top layer (methanol/water phase). This procedure was repeated once with addition of $400 \mu \mathrm{l}$ methanol, $300 \mu \mathrm{l}$ water, and $100 \mu \mathrm{l}$ chloroform.

Cerebral cortex samples were homogenized (Vibra Cell sonicator, model VCX 750, Sonics and Materials) in $500 \mu$ l methanol, before being subjected to a similar water/methanol-chloroform extraction method, as above: that is, $200 \mu \mathrm{l}$ water and $200 \mu \mathrm{l}$ chloroform were added before mixing, centrifugation was performed at $3000 \times g$ at $4^{\circ} \mathrm{C}$ for $15 \mathrm{~min}$, and 
top layer (methanol/water phase) was collected. This extraction procedure was repeated three times on the tissue sample and with addition of (first repeat) $400 \mu \mathrm{l}$ methanol, $300 \mu \mathrm{l}$ water, and $100 \mu \mathrm{l}$ chloroform or (second repeat) $200 \mu \mathrm{l}$ methanol and $150 \mu \mathrm{l}$ water. The methanol/water phases were combined and proteins removed by two-step precipitation: that is, (1) addition of $200 \mu \mathrm{l}$ chloroform and $1500 \mu \mathrm{l}$ water, mixing, centrifugation at $3000 \times g$ at $4^{\circ} \mathrm{C}$, and collection of top layer; and (2) addition of $500 \mu \mathrm{l}$ water and $100 \mu \mathrm{l}$ methanol to remaining pellet and bottom layer, mixing, centrifugation at $3000 \times g$ at $4^{\circ} \mathrm{C}$, and collection of top layer. Top layers were combined and kept at $-20^{\circ} \mathrm{C}$ for further analysis.

Brain and plasma extracts were lyophilized, reconstituted in $200 \mu \mathrm{l}$ deuterium oxide, relyophilized, and dissolved in $50 \mu \mathrm{l}$ deuterium oxide containing $8 \mathrm{~mm}$ [2,2,3,3-d(4)-3-(trimethylsilyl)-propionic acid sodium salt (Sigma-Aldrich) and $0.2 \% \mathrm{v} / \mathrm{v}$ ethylene glycol (Merck) as internal standards for quantification using ${ }^{13} \mathrm{C}$ and ${ }^{1} \mathrm{H}$ NMR (see Fig. $1 A$ ).

Metabolic mapping using ${ }^{13} \mathrm{C}$ and ${ }^{1} \mathrm{H}$ nuclear magnetic resonance (NMR) spectroscopy. ${ }^{1} \mathrm{H}$ and ${ }^{13} \mathrm{C}$ NMR spectra were recorded for plasma and brain samples to assess the amount of total and ${ }^{13} \mathrm{C}$-labeled metabolites, respectively. In particular, from ${ }^{1} \mathrm{H}$ NMR spectra total metabolite content was determined by integrating the relevant peaks and using ethylene glycol as internal standard. The metabolites quantified were glutamate, aspartate, glutamine, alanine, lactate, phosphocreatine, creatine, fumarate, tyrosine, succinate, taurine, myo-inositol, $\mathrm{N}$-acetyl aspartate, and GABA. From the ${ }^{13} \mathrm{C}$ NMR spectra, the content of ${ }^{13} \mathrm{C}$-labeled glutamate and glutamine was determined using ethylene glycol as an internal standard with a known amount of ${ }^{13} \mathrm{C}$. Corrections for natural abundance as well as nuclear Overhauser enhancement and relaxation effects relative to the internal standard were applied to all relevant integrals from the ${ }^{13} \mathrm{C}$ spectra. Percentage ${ }^{13} \mathrm{C}$ labeling was derived from the combination of quantitative data obtained from ${ }^{13} \mathrm{C}$ and ${ }^{1} \mathrm{H}$ NMR spectra.

Spectra were obtained using a $600 \mathrm{MHz}$ Avance III (Bruker BioSpin) equipped with cryogenically cooled $1.7 \mathrm{~mm}$ inverse TXI-probe. ${ }^{1} \mathrm{H}$ NMR spectra were acquired using a pulse angle of $90^{\circ}, 12 \mathrm{kHz}$ spectral width with 64,000 data points, acquisition time of $2.66 \mathrm{~s}$, relaxation delay of $10 \mathrm{~s}$, and 128 scans. Proton decoupled ${ }^{13} \mathrm{C}$-NMR spectra were obtained using $30^{\circ}$ pulse angle and $30 \mathrm{kHz}$ spectral width with 98,000 data points using an acquisition time of $1.65 \mathrm{~s}$, a relaxation delay of $0.5 \mathrm{~s}$, and 1024 scans. TopSpin 3.2 software (Bruker BioSpin) was used for acquisition, processing, and analysis.

Analysis and interpretation of ${ }^{13} \mathrm{C}$ labeling data. $\left[1-{ }^{13} \mathrm{C}\right]$ Glucose is taken up by both neurons and astrocytes (Hassel et al., 1995; Qu et al., 2000) and reflects neuronal energy metabolism and the formation of glutamine in astrocytes from glutamate synthesized in neurons (Hassel et al., 1995; Qu et al., 2000; Lundgaard et al., 2015). [1- $\left.{ }^{13} \mathrm{C}\right]$-glucose is metabolized to $\left[3-{ }^{13} \mathrm{C}\right]$-pyruvate, which can enter the mitochondria and be converted to $\left[2-{ }^{13} \mathrm{C}\right]$-acetyl-CoA (see Fig. $1 D$ ). Tricarboxylic acid (TCA) cycle metabolism of $\left[2-{ }^{13} \mathrm{C}\right]$ acetyl-CoA gives rise to $\left[2-{ }^{13} \mathrm{C}\right]$ citrate, $\left[4-{ }^{13} \mathrm{C}\right]$ glutamate, and $\left[4-{ }^{13} \mathrm{C}\right]$ glutamine (Walls et al., 2014). Unlike glucose, acetate is primarily metabolized by astrocytes (Sonnewald et al., 1993), the first step being conversion of $\left[1,2-{ }^{13} \mathrm{C}\right]$ acetate to $\left[1,2-{ }^{13} \mathrm{C}\right]$ acetyl-CoA (see Fig. $1 E$ ). TCA cycle metabolism of $\left[1,2-{ }^{13} \mathrm{C}\right]-$ acetyl-CoA gives rise to $\left[1,2-{ }^{13} \mathrm{C}\right]$-citrate, $\left[4,5-{ }^{13} \mathrm{C}\right]$-glutamate, and $[4,5$ $\left.{ }^{13} \mathrm{C}\right]$-glutamine.

Verification of glutamate and aspartate content by high-performance liquid chromatography (HPLC). Cerebral cortex was dissected from 5 synGLT-1-KO (GLT-1 ${ }^{\text {flox/flox; }}$ syn-Cre ${ }^{+}$) and 4 littermate controls (GLT-1 ${ }^{\text {flox/flox; }}$ syn-Cre ${ }^{-}$), ages $19-20$ weeks, and 5 wild-type control (WT) mice expressing synapsin-Cre (GLT- $1^{\mathrm{w} / \mathrm{w}}$; syn-Cre ${ }^{+}$), and 7 littermate controls (GLT- $1^{\mathrm{w} / \mathrm{w}}$; syn-Cre ${ }^{-}$), ages $36-44$ weeks, all male on a 129XC57BL/6J background. Tissue samples were immediately placed in microcentrifuge tubes and flash frozen with liquid nitrogen. Frozen tissue was weighed and sonicated $(1: 10 \mathrm{w}: \mathrm{v})$ in ice-cold $0.03 \mathrm{~N}$ perchloric acid solution. Protein and cellular debris were cleared by centrifugation at $20,000 \times g$ at $4^{\circ} \mathrm{C}$ for $45 \mathrm{~min}$. Pellets were resuspended in $100 \mu \mathrm{l} 0.1 \mathrm{~N}$ $\mathrm{NaOH}$, and protein content was measured using a Micro BCA Protein Assay Kit (Thermo Fisher Scientific). For sample derivatization, $20 \mathrm{mg}$ o-phthalaldehyde was dissolved in $1 \mathrm{ml}$ methanol, $10 \mathrm{mg} \mathrm{N}$-acetyl-L- cysteine, and $9 \mathrm{ml} 0.5 \mathrm{M}$ carbonate buffer, $\mathrm{pH}$ 10. Stock derivatizing reagent was stable for $5 \mathrm{~d}$ at $4^{\circ} \mathrm{C}$. Working reagent was prepared fresh daily by diluting $1 \mathrm{ml}$ of stock reagent into $4 \mathrm{ml} 0.5 \mathrm{M}$ carbonate buffer, $\mathrm{pH}$ 10. Derivatization was performed by mixing $50 \mu \mathrm{l}$ working reagent with $50 \mu \mathrm{l}$ 1:10 tissue sample diluted in water. Samples were injected using a refrigerated autosampler (System Gold 508, Beckman Coulter) into an HPLC system consisting of an Atlantis $5 \mu \mathrm{m} \mathrm{dC18} 4.6 \mathrm{~mm} \times 250$ $\mathrm{mm}$ chromatographic column, and a coulometric electrochemical detector (Coulochem III; Thermo Fisher Scientific). Oxidation and reduction electrode potentials of the analytical cell (6011; Thermo Fisher Scientific), respectively, were set at 150 and $550 \mathrm{mV}$. The mobile phase consisting of $100 \mathrm{~mm} \mathrm{Na}_{2} \mathrm{HPO}_{4}, 22 \%$ (v/v) methanol and 3.5\% acetonitrile, $\mathrm{pH}$ adjusted to 6.75 with phosphoric acid, was pumped at $0.25 \mathrm{ml} / \mathrm{min}$ by a solvent delivery module (System Gold 125, Beckman Coulter). Aspartate and glutamate content was normalized to sample protein.

\section{Isolated mitochondria}

Preparation of isolated mitochondria from mouse brain regions. Cerebral cortical mitochondria were isolated from 3 synGLT-1 KO and 3 control mice (8-20 weeks of age) in tandem. All procedures were performed on ice or at $4^{\circ} \mathrm{C}$. Animals were killed by cervical dislocation, and the brain was quickly submerged in ice-cold aCSF containing the following (in mм): $\mathrm{NaCl} 128, \mathrm{NaHCO}_{3} 25$, D-glucose 10, $\mathrm{KCl} 3, \mathrm{CaCl}_{2} 2, \mathrm{MgSO}_{4} 1.2$, $\mathrm{KH}_{2} \mathrm{PO}_{4}$ 0.4, $\mathrm{pH}$ 7.4. The cerebral cortices were dissected and mitochondria were isolated by a Percoll gradient as described previously (Andersen et al., 2017a). Protein amounts were determined by the Bradford method.

Oxygen consumption measurement. The oxygen consumption rate (OCR, $\mathrm{pmol} / \mathrm{min}$ ) of isolated cerebral cortical mitochondria was assessed at $37^{\circ} \mathrm{C}$ using a Seahorse XFe96 analyzer (Seahorse Biosciences). Mitochondria were suspended in assay buffer containing the following (in mM): mannitol 220, sucrose 70, $\mathrm{KH}_{2} \mathrm{PO}_{4} 10, \mathrm{MgCl}_{2} 5$, HEPES 2, and $0.2 \% \mathrm{BSA}$ (fatty acid free), $\mathrm{pH} 7.2 ; 4 \mu \mathrm{g}$ of protein was added to each well, and the plate was centrifuged $(2000 \times g$ for $20 \mathrm{~min})$ at $4^{\circ} \mathrm{C}$. The mitochondria were provided $37^{\circ} \mathrm{C}$ assay buffer containing $10 \mathrm{~mm}$ pyruvate with $2 \mathrm{~mm}$ malate or $10 \mathrm{~mm}$ glutamate with $10 \mathrm{~mm}$ malate (all final concentrations) and analyzed immediately. During the course of measurements, four compounds were injected in the following order: ADP (4 mM), oligomycin A $(2.5 \mu \mathrm{g} / \mathrm{ml})$, carbonyl cyanide-p-trifluoromethoxyphenylhydrazone (FCCP, $8 \mu \mathrm{M})$, and antimycin A $(8 \mu \mathrm{M})$, all final concentrations. OCRs were calculated using the Wave software (Seahorse Biosciences). Baseline refers to OCR before addition of compounds. Relative OCR levels were calculated by setting the OCR at the third baseline measurement to $100 \%$.

ATP production measurement. The ATP synthesis rate $(\mathrm{nmol} /(\mathrm{min} \times$ $\mathrm{mg}$ ) of isolated cerebral cortical mitochondria was assessed at $28^{\circ} \mathrm{C}$ with a luminescence assay, based on the reaction of ATP and luciferin catalyzed by luciferase, using a NOVOstar plate reader (BMG Labtech). The isolated mitochondria were diluted in assay buffer, containing the following (in mM): sucrose $250, \mathrm{~K}_{2} \mathrm{HPO}_{4} 15, \mathrm{MgSO}_{4} 2$, EDTA 0.5 , and $0.5 \%$ BSA (fatty acid free), $\mathrm{pH} 7.2$, and $2.5 \mu \mathrm{g}$ of protein was added to each well. The wells contained either pyruvate or glutamate, and P1,P5diadenosine pentaphosphate, in final concentrations of $5 \mathrm{~mm}$ and $10 \mu \mathrm{M}$, respectively. During the measurement period, three injections were performed: (1) a luciferin-luciferase mixture was injected to establish the background luminescence; (2) subsequently, $2 \mathrm{~mm} \mathrm{ADP}$ in combination with $2.5 \mathrm{~mm}$ malate (final concentrations) was injected; and (3) last, 250 $\mu \mathrm{M}$ ATP was injected as an internal standard for determination of the produced amount of ATP. The apparatus and suspensions were preheated to $28^{\circ} \mathrm{C}$ for optimal luciferin-luciferase response.

\section{Electron microscopic analysis in cerebral cortical tissue}

Cerebral cortical tissue of 3 synGLT-1 KO and 3 controls (P50-P59) were immunolabeled for GLT-1 using HRP-DAB-osmium as described previously (Petr et al., 2015). The GLT-1a antibody (gift from Dr. Jeff Rothstein, Johns Hopkins) was diluted 1:10,000 or 1:30,000, previously shown to immunolabel presynaptic terminals of excitatory neurons and astrocytes specifically (Petr et al., 2015). Electron microscopic images were captured at a magnification of $30,000 \times$, spanning $28.5 \mu \mathrm{m}^{2}$ per 
micrograph. Imaging was conducted by sweeping across surface-most portions of immunolabeled vibratome sections systematically and strictly in the order of encounter, to avoid synaptic reencounters and ensure random sampling, until the number of profiles of asymmetric (presumably excitatory) synaptic junctions reached 100 per animal. Because there were 3 animals per genotype, the total number of excitatory synapses analyzed per genotype was 300 .

Within the neuropil area occupying 100 excitatory synaptic junctions, the following were assessed (axis denomination for graphical representation of results in parentheses): (1) averaged number of presynaptic mitochondrial profiles, per every group of 10 excitatory synaptic profiles encountered ("presynaptic mitochondria per 10 synapses"); (2) average number of mitochondrial profiles within perisynaptic astrocytic profiles, per every group of 10 synapses ("perisynaptic astrocytic mitochondria, per 10 synapses"); and (3) average number of astrocytic mitochondrial profiles encountered per unit area of $28.5 \mu \mathrm{m}^{2}$ spanning the area of one micrograph ("astrocytic mitochondria, per unit area"). To assess the efficiency of GLT-1 KO from neurons, the same set of micrographs were used to determine the frequency of GLT-1 immunoreactivity within axon terminals forming excitatory synapses, per every group of 10 synapses, the occurrence of tripartite synapses (synapses abutted by astrocytic processes at synaptic cleft margins), and the proportion of synaptically associated astrocytic profiles with GLT-1 immunoreactivity.

To determine whether synGLT1-KO altered efficiency of ATP synthesis by mitochondria, the same set of micrographs were used to analyze mitochondrial cristae density. This value was assessed by measuring the distance between two or more adjacent cristae at the point of junction with the inner mitochondrial membrane, as described by Gomes et al. (2011). This measurement was repeated for 20 mitochondria per animal, or 60 mitochondria per genotype group (reported in graph as "Distance between neighboring cristae"). All values were pooled across tissue derived from the same genotype, for assessing whether the values differed significantly across the genotypes.

\section{Synaptosomal glutamate uptake and metabolism}

Isolation of synaptosomes. Purified cerebral cortical synaptosomes for determination of OCR and glycolytic activity were prepared from 5 synGLT-1 KO and 5 control mice (36-40 weeks of age), whereas purified cerebral cortical synaptosomes for incubations with ${ }^{13} \mathrm{C}$-substrates were prepared from 5 synGLT-1 KO and 4 control mice (8-20 weeks of age), both by using a modification of a previously published Percoll gradient method (Hohnholt et al., 2017).

For preparation of purified synaptosomes, mice were killed by cervical dislocation; the cerebral cortex isolated and homogenized in a Teflon/ glass homogenizer (Wheaton). The homogenate was centrifuged at $800 \times g$ for $10 \mathrm{~min}$ at $4^{\circ} \mathrm{C}$ in a precooled JA-20 rotor (Beckman Coulter) and the supernatant diluted to a final volume of $8 \mathrm{ml}$ with ice-cold sucrose/EDTA buffer containing $250 \mu \mathrm{m}$ DTT final concentration. The homogenate was layered on top of a Percoll gradient (3\%,10\%, and 23\% in ice-cold sucrose/EDTA buffer containing $250 \mu \mathrm{M}$ DTT) and centrifuged at $31,400 \times g\left(5 \mathrm{~min}, 4^{\circ} \mathrm{C}\right)$. The layer above $23 \%$ Percoll contains synaptosomes and was removed with a glass pipette, resuspended in ice-cold sucrose/EDTA buffer, and centrifuged $(20,000 \times g, 15 \mathrm{~min}$, $\left.4^{\circ} \mathrm{C}\right)$. The pellet was transferred to an Eppendorf tube and carefully resuspended in ice-cold sucrose/EDTA buffer. The amount of synaptosomes was determined by the Bradford protein determination according to the manufacturer's instructions (Sigma-Aldrich) using BSA as standard protein.

Crude synaptosomes were used for glutamate uptake studies. These were prepared from cerebral cortex of 6 synGLT-1 KO and 6 control mice ( $8-10$ weeks of age) without sucrose gradient purification, as previously described (Petr et al., 2015). Mice were anesthetized using ether, and brains were removed. The cerebral cortex was dissected, weighed, and homogenized in ice-cold $0.32 \mathrm{M}$ sucrose solution $(20 \mathrm{ml}$ solution/g tissue) containing Halt Protease and Phosphatase Inhibitor Mixture (Thermo Fisher Scientific, catalog \#78440). Samples were centrifuged at $800 \times g$ for $10 \mathrm{~min}$ at $4^{\circ} \mathrm{C}$. The supernatant was poured into a fresh tube and centrifuged at $20,000 \times g$ for $20 \mathrm{~min}$ at $4^{\circ} \mathrm{C}$. The pellet was then resuspended in ice-cold $0.32 \mathrm{M}$ sucrose $(40 \mathrm{ml}$ solution/g tissue) and centrifuged at $20,000 \times g$ for $20 \mathrm{~min}$ at $4^{\circ} \mathrm{C}$. The washed pellet was then resuspended in ice-cold $0.32 \mathrm{M}$ sucrose $(50 \mathrm{ml}$ solution/g pellet) by homogenization.

Oxygen consumption and glycolytic activity assessment. The OCR $(\mathrm{pmol} / \mathrm{min})$ and extracellular acidification rate (ECAR, $\mathrm{mpH} / \mathrm{min}$ ) of isolated purified cerebral cortical synaptosomes were assessed at $37^{\circ} \mathrm{C}$ using a Seahorse XFe96 analyzer (Seahorse Biosciences) with a protocol adapted from Choi et al. (2009). Briefly, isolated synaptosomes were suspended in salt solution containing the following (in $\mathrm{mM}$ ): $\mathrm{NaCl} 120$, $\mathrm{KCl} 3.4, \mathrm{MgSO}_{4} 2, \mathrm{CaCl}_{2} 1.3, \mathrm{Na}_{2} \mathrm{SO}_{4} 1.2, \mathrm{KH}_{2} \mathrm{PO}_{4} 0.4$, and $0.4 \%$ BSA (fatty acid free), $\mathrm{pH} 7.4 ; 8 \mu \mathrm{g}$ of protein was added to each well, and the plate was centrifuged $(3400 \times g$ for $20 \mathrm{~min})$ at $4^{\circ} \mathrm{C}$. The synaptosomes were provided $37^{\circ} \mathrm{C}$ salt solution containing either $5 \mathrm{~mm}$ glucose or $5 \mathrm{~mm}$ glucose supplemented with $0.1 \mathrm{~mm}$ glutamate (all final concentrations). During the course of measurements, four compounds were injected in the following order: veratridine $(5 \mu \mathrm{M})$, oligomycin A $(6 \mu \mathrm{M})$, FCCP $(4$ $\mu \mathrm{M})$, and antimycin A in combination with rotenone $(2+2 \mu \mathrm{M})$, all final concentrations. OCR and ECAR were calculated using the Wave software (Seahorse Biosciences). Baseline refers to OCR and ECAR before addition of compounds. Relative ECAR levels and OCR levels for veratridine, oligomycin $\mathrm{A}$, and antimycin $\mathrm{A} /$ rotenone conditions were calculated by setting the second baseline measurement to $100 \%$. Due to decline of synaptosomal OCR during the measurement period (Hohnholt et al., 2017), the relative OCR level for the FCCP condition was calculated by setting the sixth measurement (i.e., the measurement immediately before FCCP addition) to $100 \%$.

Synaptosomal glutamate uptake. The KO of GLT-1 expression in axonal terminals of cerebral cortex was verified in crude synaptosomes from synGLT-1 KO and control animals by determining sodiumdependent transport of L- $\left[{ }^{3} \mathrm{H}\right]$ glutamate as previously described (Petr et al., 2015). The isolated crude synaptosomes in $0.32 \mathrm{~m}$ sucrose were kept on ice and used immediately for the uptake assay. Glass tubes containing $450 \mu$ l of buffer [in mM: $\mathrm{NaCl} \mathrm{140,} \mathrm{or} \mathrm{choline} \mathrm{chloride} 140, \mathrm{KCl} 2.5, \mathrm{CaCl}_{2}$ 1.2, $\mathrm{MgCl}_{2} 1.2, \mathrm{~K}_{2} \mathrm{HPO}_{4}$ 1.2, glucose 10, 2-amino-2-(hydroxymethyl) propane-1,3-diol (Tris base) 5, HEPES 10] with $10 \mu \mathrm{M}$ L-glutamate [including $0.005 \mu \mathrm{M} \mathrm{L}-\left[{ }^{3} \mathrm{H}\right]$ glutamate (PerkinElmer)] were preincubated for $5 \mathrm{~min}$ at $37^{\circ} \mathrm{C}$. Glutamate uptake into synaptosomes was initiated by adding $50 \mu \mathrm{l}$ of crude synaptosomes to each tube and incubating at $37^{\circ} \mathrm{C}$ for $30 \mathrm{~s}$. To stop uptake activity, $2 \mathrm{ml}$ of ice-cold choline buffer was added to the tube, which was then vortexed and plunged into an ice-water slurry. The samples were filtered through Whatman GF/C filter paper prewetted with $2 \mathrm{ml}$ choline buffer, and the filters were washed three times with $2 \mathrm{ml}$ ice-cold choline buffer. Radioactivity on the filters was measured by liquid scintillation counting (Tri-Carb 2200CA, Packard; Long Island Scientific). The radioactivity taken up by the synaptosomes in the absence of sodium was subtracted from that taken up in the presence of sodium to determine the sodium-dependent component of transport. Glutamate uptake values were determined by normalizing the radioactivity count by protein concentration of the crude synaptosomes isolated from each brain region. Protein concentration was quantified using the DC protein assay (Bio-Rad).

Incubation of synaptosomes with substrates. Purified synaptosomes from cerebral cortex ( $0.3 \mathrm{mg}$ synaptosomal protein/condition) were incubated for $45 \mathrm{~min}$ at $37^{\circ} \mathrm{C}$ in incubation medium (DMEM without FCS, $\mathrm{pH}$ 7.4, DMEM) containing $2.5 \mathrm{~mm}\left[\mathrm{U}-{ }^{13} \mathrm{C}\right]$-glucose and $0.1 \mathrm{~mm}$ unlabeled glutamate or $0.1 \mathrm{~mm}\left[\mathrm{U}_{-}{ }^{13} \mathrm{C}\right]$-glutamate and $2.5 \mathrm{~mm}$ unlabeled glucose. The incubation was terminated by centrifugation $(1000 \times g, 2$ $\min , 4^{\circ} \mathrm{C}$ ), and the synaptosomes were washed once with PBS and extracted with 70\% ice-cold ethanol. The synaptosome extracts and incubation media were lyophilized and stored $\left(-20^{\circ} \mathrm{C}\right)$ until further analysis by gas chromatography coupled to mass spectrometry (GC-MS), HPLC (Andersen et al., 2017b), and lactate assay kit (R-Biopharm AG). Protein content was determined using the Pierce bicinchoninic acid protein assay.

Analysis and interpretation of ${ }^{13}$ C labeling data. The main cellular constituents of purified synaptosomes are neuronal presynaptic and postsynaptic vesicular structures. Hence, the ${ }^{13} \mathrm{C}$ labeling in metabolites detected in purified synaptosomes, subsequent to incubations with $\left[\mathrm{U}-{ }^{13} \mathrm{C}\right]$-glucose or $\left[\mathrm{U}-{ }^{13} \mathrm{C}\right]$-glutamate, represents neuronal metabo- 
lism. $\left[\mathrm{U}_{-}{ }^{13} \mathrm{C}\right]$-glucose metabolism results in $\left[\mathrm{U}_{-}{ }^{13} \mathrm{C}\right]$-pyruvate, alanine, and lactate following glycolysis, and double-labeled TCA cycle intermediates and amino acids during first turn of the TCA cycle. Incubation with $\left[\mathrm{U}-{ }^{13} \mathrm{C}\right]$-glutamate introduces ${ }^{13} \mathrm{C}$ labeling at another point in the metabolic pathways. In particular, aminotransferase and glutamate dehydrogenase $(\mathrm{GDH})$ activity mediates label entry into the TCA cycle giving rise to quadruple ${ }^{13} \mathrm{C}$ labeling in TCA cycle intermediates (Walls et al., 2014). GC-MS provides the number of ${ }^{13} \mathrm{C}$-atoms incorporated in a metabolite; hence, the designation "metabolite $\mathrm{M}+n$ " (M: molecular weight; $n$ : between 1 and the total number of $\mathrm{C}$ atoms in the molecule). The higher sensitivity of GC-MS compared with NMR results in detection of ${ }^{13} \mathrm{C}$ labeling in TCA cycle intermediates and aspartate in addition to glutamate and glutamine.

\section{Experimental design and statistical analysis}

For this study, only male mice were included to avoid potential confounding variation introduced by sex differences. Sample sizes were based on pilot studies and previous experience. Student's $t$ test was used when comparing synGLT-1 KO and control, except for the EM data for which the Kolmogorov-Smirnov test were applied. To reduce the possibility of Type I error, we regarded $p<0.05$ (indicated by an asterisk in the figures) as statistically significant. To correct for multiple comparisons, we used the Benjamini-Hochberg procedure with a critical value for false discovery of 0.10 (Benjamini and Hochberg, 1995). For Student's $t$ tests, $t$ values, degrees of freedom, and $p$ values are reported. For KolmogorovSmirnov tests, $D$ values and $p$ values are reported. All statistical information, including sample sizes for each genotype group $(n)$, are described in the figure legends or in the main text. All data are represented as mean \pm SEM. All statistical analyses were conducted using Prism (GraphPad).

\section{Results}

GLT-1 is expressed in axon terminals in the cerebral cortex (Melone et al., 2009, 2011; de Vivo et al., 2010; Capuani et al., 2016; Zhou et al., 2019). Four types of experiments were conducted to assess the metabolic function in cerebral cortex of synGLT-1 KO and littermate control mice: (1) in vivo metabolic mapping to investigate neuronal and astrocyte energy metabolism; (2) assays of oxygen consumption and ATP production in isolated mitochondria; (3) electron microscopy, to assess mitochondrial prevalence within perisynaptic astrocyte processes and neurons; and (4) assessment of oxygen consumption, glycolytic activity, glutamate uptake, and metabolic ${ }^{13} \mathrm{C}$ labeling experiments in purified synaptosome preparations to separate out changes specific to synapses.

\section{In vivo metabolic mapping}

\section{Animal and blood plasma measures}

Blood plasma was successfully obtained from 10 of the 14 mice ( 6 synGLT-1 KO and 4 controls). Despite significantly lower body weight of synGLT-1 KO compared with control mice ( $32 \pm 1$ and $\left.41 \pm 2 \mathrm{~g}, t_{(12)}=3.819, p=0.0024, n=7\right)$, no significant differences were observed regarding ${ }^{13} \mathrm{C}$ enrichment of the injected substrates in plasma $\left(27 \pm 4 \%\right.$ and $26 \pm 4 \%$ at glucose $C 1, t_{(8)}=$ $0.2259, p=0.8269, n=4-6 ; 84 \pm 1 \%$ and $86 \pm 1 \%$ at acetate $\left.\mathrm{C} 1,2, t_{(8)}=1.234, p=0.2521, n=4-6\right)$, or in the extracts of cerebral cortex $\left(27 \pm 2 \%\right.$ and $28 \pm 2 \%$ at glucose $\mathrm{C} 1, t_{(12)}=$ $0.3227, n=7 ; 43 \pm 8 \%$ and $36 \pm 12 \%$ at acetate $\mathrm{C} 1,2, t_{(12)}=$ $0.4707, n=7)$. Hence, differences observed in metabolite content or ${ }^{13} \mathrm{C}$ labeling between synGLT-1 KO and controls are likely to be caused by the genetic alteration and not a consequence of differences in plasma concentrations of injected substrates.

\section{Total metabolite concentrations in brain}

Tissue from cerebral cortex ( $167 \pm 5 \mathrm{mg}, n=14$ ) was successfully collected from 7 synGLT-1 KO and 7 control mice following injection with $\left[1-{ }^{13} \mathrm{C}\right]$-glucose/ $\left[1,2-{ }^{13} \mathrm{C}\right]$ acetate (Fig. $1 A$ ). The concentrations of total (labeled and unlabeled) glutamate, glutamine, and aspartate and other metabolites in cerebral cortex tissue were obtained by ${ }^{1} \mathrm{H}-\mathrm{NMR}$ spectroscopy. The concentration of aspartate in cerebral cortex of synGLT-1 KO mice was significantly reduced (by $\sim 57 \%, t_{(12)}=2.315, p=0.04, n=7$; Fig. $1 B$ ) compared with controls, whereas the glutamate level was maintained in the synGLT- $1 \mathrm{KO}(9.5 \pm 0.1$ and $9.5 \pm 0.6 \mu \mathrm{mol} / \mathrm{g}$ tissue, $\left.t_{(12)}=0.135, p=0.89, n=7\right)$.

The expression of Cre-recombinase (Cre) is known to produce a variety of off target effects in eukaryotic cells (Lee et al., 2006; Schmidt-Supprian and Rajewsky, 2007; Harno et al., 2013; Hu et al., 2013; Stuber et al., 2015). Therefore, it was important to pursue the possibility that the changes in aspartate content observed in synGLT-1 KO mice were a consequence of expression of synapsin-Cre in itself. Hence, in another cohort of animals, we assayed aspartate and glutamate concentrations by HPLC in extracts of cerebral cortex from 7 WT mice $\left(\right.$ GLT- ${ }^{\text {w/w }}$; syn-Cre ${ }^{-}$) and 5 littermates expressing the synapsin-Cre (GLT- ${ }^{\mathrm{w} / \mathrm{w}}$; syn$\mathrm{Cre}^{+}$). In the same experiment, as a positive control, we also assayed aspartate and glutamate concentrations in 5 synGLT-1 $\mathrm{KO}$ mice (GLT-1 ${ }^{\text {flox/flox; }}$ syn-Cre ${ }^{+}$) and 4 littermate controls (GLT-1 ${ }^{\text {flox/flox }}$; syn-Cre ${ }^{-}$). We confirmed the finding of reduced aspartate concentration (by $\sim 44 \% ; t_{(7)}=3.599, p=0.01, n=4$ or 5; Fig. 1C) and maintained glutamate levels (19 \pm 0.4 and $20 \pm$ $1.4 \mu \mathrm{mol} / \mathrm{g}$ tissue, $t_{(7)}=0.5525, p=0.598, n=4$ or 5$)$ in the

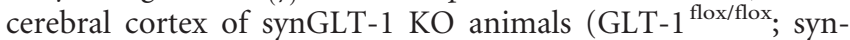
$\mathrm{Cre}^{+}$) compared with littermate controls (GLT-1 ${ }^{\text {flox/flox }}$; syn$\left.\mathrm{Cre}^{-}\right)$. Importantly, expression of synapsin-Cre in mice of the same WT GLT-1 background (GLT-1 ${ }^{\mathrm{w} / \mathrm{w}}$; syn-Cre ${ }^{-}$) versus $\left(\right.$ GLT- $1^{\mathrm{w} / \mathrm{w}}$; syn-Cre $\left.{ }^{+}\right)$had no effect on aspartate $\left(t_{(10)}=1.04\right.$, $p=0.323, n=5-7$; Fig. $1 C)$ or glutamate content $(20 \pm 1$ and $19 \pm 2 \mu \mathrm{mol} / \mathrm{g}$ tissue, $\left.t_{(10)}=0.8676, p=0.406, n=5-7\right)$.

All other metabolites measured by ${ }^{1} \mathrm{H}-\mathrm{NMR}$ (alanine, lactate, phosphocreatine, creatine, fumarate, tyrosine, succinate, taurine, myo-inositol, $N$-acetyl aspartate, glutamine, and GABA) were not significantly altered in synGLT-1 KO animals $(p>0.05, n=$ 7 ; individual $p$ values are stated in Table 1$)$. The lack of effects of the $\mathrm{KO}$ on metabolite pools, other than on aspartate, including levels of $N$-acetyl aspartate, which is an indicator of neuronal health (Moffett et al., 2007), suggests no neurodegeneration or other deleterious effects on neuronal survival in these mice.

Cerebral metabolism of $\left[1-{ }^{13} \mathrm{C}\right]$-glucose

${ }^{13} \mathrm{C}-\mathrm{NMR}$ spectroscopy was performed on brain tissue extracts to obtain more detailed information about amino acid metabolism in neurons and astrocytes, and interactions between cellular compartments. $\left[1-{ }^{13} \mathrm{C}\right]$ Glucose-derived metabolites primarily reflect neuronal energy metabolism and the formation of glutamine in astrocytes from glutamate synthesized in neurons (Hassel et al., 1995; Qu et al., 2000; Lundgaard et al., 2015). No significant differences between synGLT-1 KO and control mice were observed in the ${ }^{13} \mathrm{C}$ labeling of glutamate or glutamine derived from the first turn of the TCA cycle metabolism of [2- ${ }^{13}$ C-acetyl-CoA $]$ generated from $\left[1-{ }^{13} \mathrm{C}\right]$ glucose, that is, [4${ }^{13} \mathrm{C}$ ] glutamate $\left(t_{(12)}=0.986, p=0.923, n=7\right)$ and $[4-$ ${ }^{13} \mathrm{C}$ ] glutamine $\left(t_{(12)}=0.61, p=0.553, n=7\right.$; Fig. $\left.1 D\right)$.

First turn of the TCA cycle metabolism of $\left[2-{ }^{13} \mathrm{C}\right]$-acetyl-CoA also leads to formation of $\left[2-{ }^{13} \mathrm{C}\right]$ and $\left[3-{ }^{13} \mathrm{C}\right]$-oxaloacetate (OAA), which upon second turn of the TCA cycle gives rise to $\left[2-{ }^{13} \mathrm{C}\right]$ glutamate and $\left[3-{ }^{13} \mathrm{C}\right]$ glutamate. Hence, the ratio [3$\left.{ }^{13} \mathrm{C}\right]$ glutamate/ $\left[4-{ }^{13} \mathrm{C}\right]$ glutamate provides an estimate of TCA cycle activity (Håberg et al., 1998). This ratio was not significantly different in brain tissue obtained from the synGLT-1 KO (0.23 \pm 
A

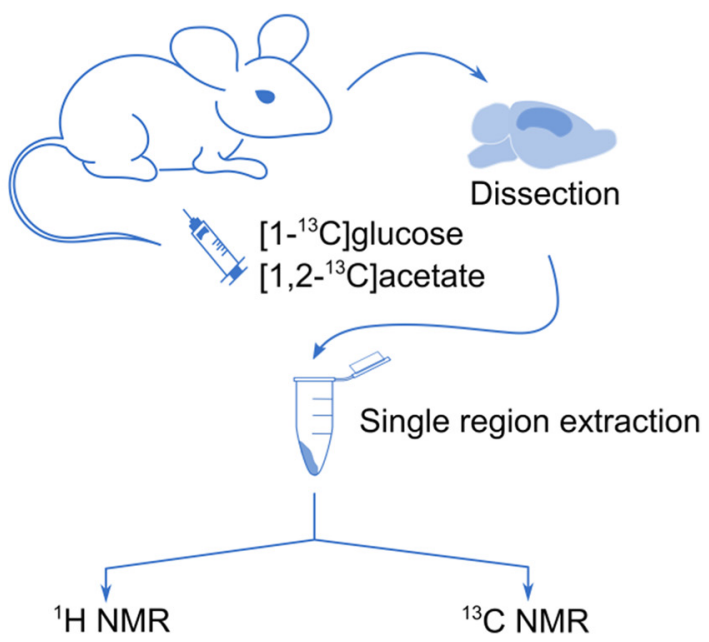

D

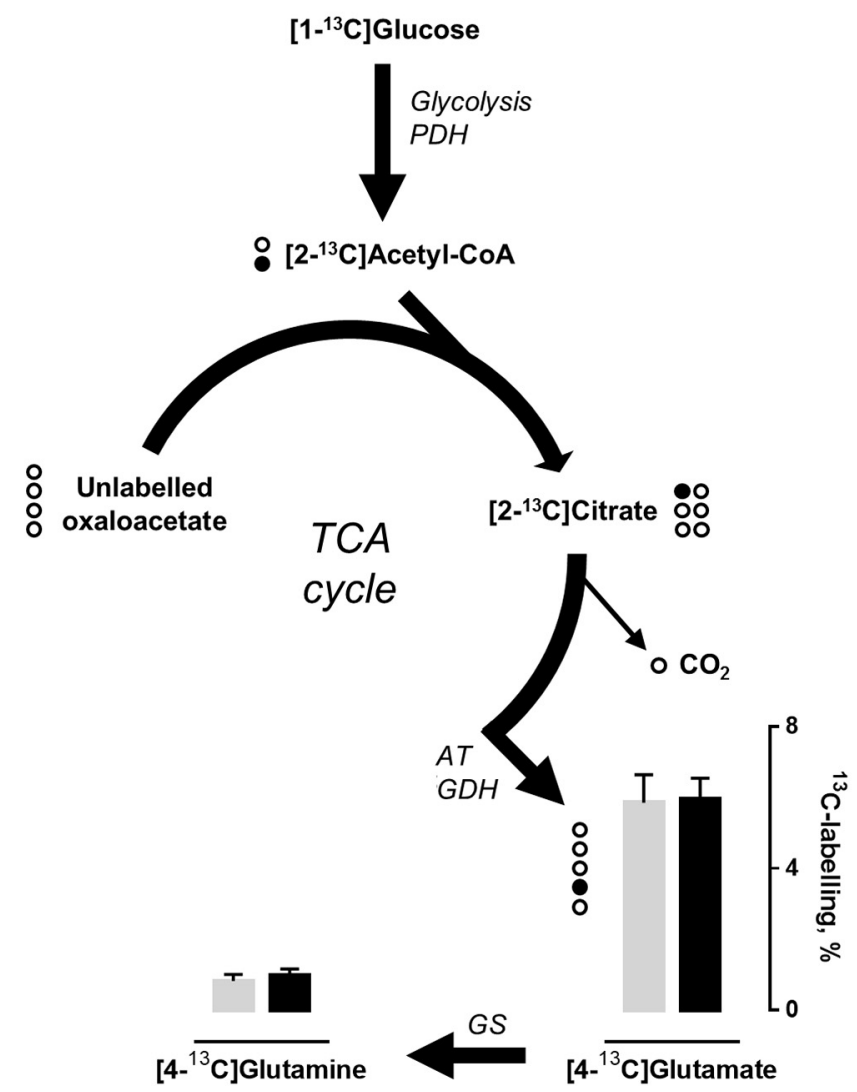

B

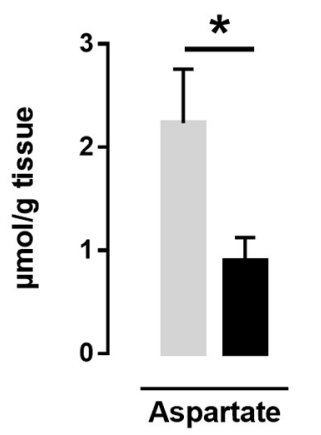

C
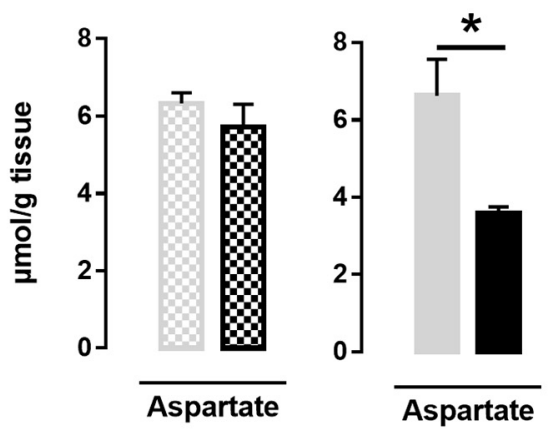

Control (GLT-1 ${ }^{\text {flox/flox; }}$ syn-Cre-)

synGLT-1 KO (GLT-1 $1^{\text {flox/flox }}$;syn-Cre+)

Wild-type control (GLT-1 ${ }^{\text {w/w }}$;syn-Cre-)

$\infty$ Cre-expression control (GLT-1 ${ }^{\text {w/w }} ;$ syn-Cre+)

E

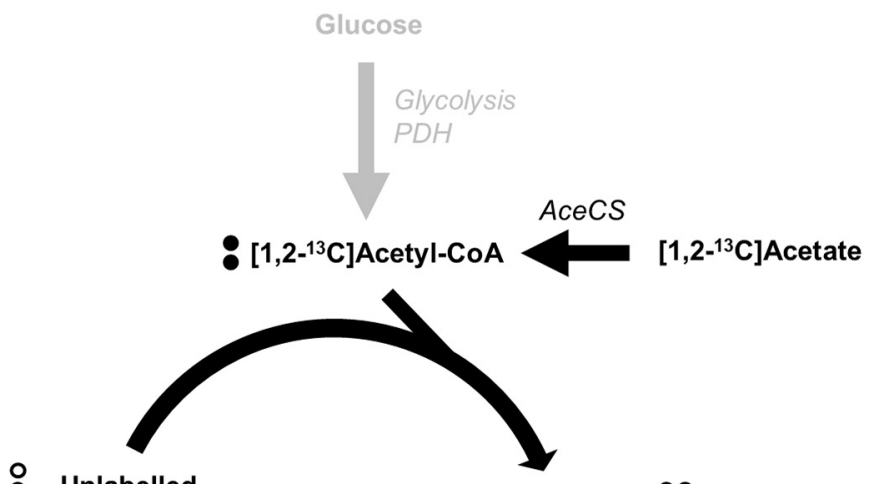

$\stackrel{\text { Unlabelled }}{: \text { oxaloacetate }} \quad$ TCA $\quad\left[1,2-{ }^{13} \mathrm{C}\right]$ Citrate $\stackrel{\circ}{\circ}$

\section{cycle}

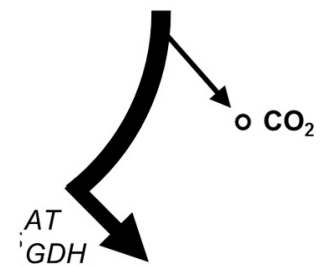

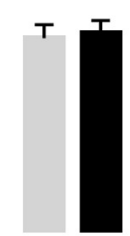

$\left[4,5-{ }^{13} \mathrm{C}\right]$ Glutamine
:

GS $\frac{0}{\circ}$

Figure 1. In vivo metabolic mapping experiments reveal reduced aspartate concentrations but detect no TCA cycle metabolism changes in cerebral cortex of synGLT-1 K0. A, Mice in which the GLT-1 gene was knocked out in neurons by expression of synapsin-Cre (synGLT-1 K0; black bars) and littermate controls (gray bars) were injected intraperitoneally with [1- $\left.{ }^{13} \mathrm{C}\right]$-glucose and $\left[1,2-{ }^{13} \mathrm{C}\right]$-acetate to assess neuronal and astrocytic metabolism, respectively, in vivo. Thirty minutes after injection, mice were killed by microwave fixation of the brain, which was then dissected, and cerebral cortex assayed for its total content of metabolites by ${ }^{1} \mathrm{H}$-NMR spectroscopy $(\boldsymbol{B}$; and Table 1$)$ and percent ${ }^{13} \mathrm{C}$ labeling by combining with ${ }^{13} \mathrm{C}-\mathrm{NMR}$ spectroscopy. The ${ }^{13} \mathrm{C}$ mapping strategy allows distinction between ${ }^{13} \mathrm{C}$ labeling originating from metabolism of $\left[1-{ }^{13} \mathrm{C}\right]$-glucose $(\boldsymbol{D})$ and $\left[1,2-{ }^{13} \mathrm{C}\right]$-acetate $(\boldsymbol{E})$. $\boldsymbol{D}, \boldsymbol{E}$, Black and white circles represent ${ }^{13} \mathrm{C}$ and ${ }^{12} \boldsymbol{C}$, respectively. $\boldsymbol{C}$, In another cohort of animals, total metabolite concentrations were assayed by HPLC in extracts of cerebral cortex from WT mice (GLT- ${ }^{\text {w/w; }}$;yn-Cre ${ }^{-} ; n=7$ ) and littermates expressing the

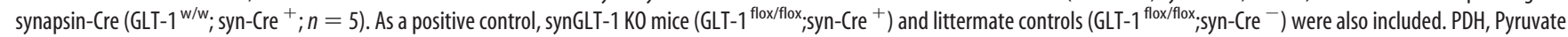
dehydrogenase; AT, aminotransferase; AceCS, acetyl-CoA synthetase; syn-Cre, synapsin-Cre. Data are mean \pm SEM. ${ }^{*} p<0.05$ (Student's test corrected for multiple comparisons). 
Table 1. Total metabolite concentrations ( $\mu \mathrm{mol} / \mathrm{g}$ tissue) in extracts of whole cerebral cortex determined by ${ }^{1} \mathrm{H}-\mathrm{NMR}^{a}$

\begin{tabular}{lrrrl}
\hline Metabolite & \multicolumn{1}{l}{ Control } & \multicolumn{1}{c}{ synGLT-1 K0 } & \multicolumn{1}{c}{$t(\mathrm{df})$} & \multicolumn{1}{c}{$p$} \\
\hline Alanine & $0.43 \pm 0.04$ & $0.47 \pm 0.09$ & $0.058(12)$ & 0.737 \\
Creatine & $5.67 \pm 0.41$ & $5.21 \pm 0.42$ & $0.787(12)$ & 0.452 \\
Phosphocreatine & $1.81 \pm 0.29$ & $1.97 \pm 0.36$ & $0.285(12)$ & 0.721 \\
Total creatine & $7.48 \pm 0.22$ & $7.18 \pm 0.30$ & $0.502(12)$ & 0.440 \\
Fumarate & $0.05 \pm 0.00$ & $0.06 \pm 0.02$ & $0.028(12)$ & 0.332 \\
GABA & $1.69 \pm 0.06$ & $1.90 \pm 0.27$ & $0.355(12)$ & 0.474 \\
Glutamate & $9.47 \pm 0.10$ & $9.54 \pm 0.60$ & $0.135(12)$ & 0.890 \\
Glutamine & $4.88 \pm 0.16$ & $4.79 \pm 0.43$ & $0.154(12)$ & 0.848 \\
Lactate & $1.55 \pm 0.13$ & $2.37 \pm 1.05$ & $1.400(12)$ & 0.454 \\
Myo-inositol & $4.83 \pm 0.11$ & $4.98 \pm 0.22$ & $0.257(12)$ & 0.559 \\
N-Acetyl aspartate & $6.05 \pm 0.16$ & $6.08 \pm 0.26$ & $0.058(12)$ & 0.913 \\
Succinate & $0.20 \pm 0.01$ & $0.17 \pm 0.01$ & $0.0507(12)$ & 0.145 \\
Taurine & $19.75 \pm 1.00$ & $19.55 \pm 1.09$ & $0.351(12)$ & 0.892 \\
Tyrosine & $0.10 \pm 0.01$ & $0.10 \pm 0.01$ & $0.001(12)$ & 0.951 \\
\hline
\end{tabular}

${ }^{a}$ This table summarizes concentrations of total (labeled and unlabeled) metabolites in extracts of cerebral cortex tissue obtained by ${ }^{1} \mathrm{H}$-NMR spectroscopy. Tissue from cerebral cortex was collected from 7 synGLT- $1 \mathrm{~K} 0$ and 7 control mice following injection with $\left[1{ }^{13} \mathrm{C}\right]$-glucose/ $\left[1,2-{ }^{13} \mathrm{C}\right]$-acetate. No significant differences were found in the concentrations of any metabolite measured, except for aspartate (see Fig. 1). Results are presented as mean \pm SEM; $n=7$. Total creatine $=$ phosphocreatine + creatine

$0.03)$ compared with controls $(0.27 \pm 0.01 ; p=0.204, n=6)$. Hence, despite the significant changes in aspartate concentrations observed in the cerebral cortex of the synGLT-1 KO, we detected no effect on neuronal energy metabolism and glutamate transfer to astrocytes.

\section{Cerebral metabolism of $\left[1,2-{ }^{13} \mathrm{C}\right]$-acetate}

$\left[1,2-{ }^{13} \mathrm{C}\right]$ Acetate is preferentially metabolized by astrocytes; hence, the resulting metabolite ${ }^{13} \mathrm{C}$ labeling primarily reflects astrocyte metabolism (Sonnewald et al., 1993). The ${ }^{13} \mathrm{C}$ enrichment $(\%)$ in glutamate and glutamine derived from $\left[1,2-{ }^{13} \mathrm{C}\right]-$ acetate following the first turn of the TCA cycle was not significantly different between the groups $\left(t_{(12)}=1.783, p=\right.$ 0.010 and $t_{(12)}=0.3216, p=0.753, n=7$; Fig. $\left.1 E\right)$. Hence, the current method likewise detects no effect of the synGLT-1 KO on astrocyte metabolism or astrocyte-neuron glutamine transfer.

\section{Oxygen consumption and ATP production in isolated mitochondria}

Glutamate contributes to the TCA cycle intermediate pool and thereby the capacity of the TCA cycle, and it is possible that the mitochondrial machinery is affected by the deletion of neuronal GLT-1. Hence, OCR and ATP production rate were investigated in mitochondria isolated from cerebral cortex (Fig. 2A).

Mitochondrial respiration was assessed in the presence of malate, to ensure availability of TCA cycle intermediates. By combining malate with either pyruvate or glutamate, which enter the TCA cycle by different metabolic pathways, it is possible to assess whether certain metabolic steps are affected by the synGLT-1 KO. In particular, glutamate can enter the TCA cycle via an aminotransferase or GDH, whereas pyruvate entry is mediated by pyruvate dehydrogenase. Mitochondrial respiration, using malate in combination with pyruvate or glutamate as respiratory substrates, was not significantly different in isolated mitochondria from synGLT-1 KO at baseline (pyruvate: $t_{(4)}=0.894$, $p=0.422$; glutamate: $t_{(4)}=2.217, p=0.091$; Fig. $2 B, E$ ) or at any of the conditions (pyruvate: $\mathrm{ADP}, t_{(4)}=0.155, p=0.884$; oligomycin $\mathrm{A}, t_{(4)}=2.22, p=0.090 ; \mathrm{FCCP}, t_{(4)}=0.145, p=0.892$; antimycin $\mathrm{A}, t_{(4)}=2.29, p=0.084$; glutamate: $\mathrm{ADP}, t_{(4)}=0.829$, $p=0.454$; oligomycin A, $t_{(4)}=0.108, p=0.919$; FCCP, $t_{(4)}=$ $0.083, p=0.937$; antimycin A, $t_{(4)}=0.751, p=0.494 ; n=3$; Fig. $2 C, F)$. In contrast, the ATP production was significantly elevated only in the presence of glutamate $\left(t_{(4)}=5.184, p=0.007, n=3\right.$; Fig. $2 G$ ) and trended toward an increase in the presence of pyruvate $\left(t_{(4)}=2.69, p=0.055, n=3\right.$; Fig. $\left.2 D\right)$. Together, these data suggest that the metabolic machinery of mitochondria is altered in the synGLT-1 KO mice. Specifically, increased ATP production in the face of unchanged oxygen consumption suggests increased mitochondrial efficiency. Moreover, because oxygen consumption was unaffected by the synGLT-1 KO when measured in the presence of either glutamate or pyruvate, it is likely that the pathways mediating glutamate and pyruvate entry into the TCA cycle are not affected by the KO. Instead, the enzymes constituting the electron transport chain (ETC) and the ATP synthase (Fig. 2A) could be affected by GLT-1 deletion in axon terminals.

\section{Prevalence of mitochondria in astrocytes and neurons}

Because our experiments on isolated mitochondria revealed altered mitochondrial metabolism in the synGLT-1 KO, we sought to use a different experimental approach to obtain evidence for alteration of mitochondrial function in the synGLT-1 KO. Therefore, we studied whether mitochondrial prevalence at the tripartite synapses might also be changed.

We first assessed the efficacy of the KO by assessing GLT-1 immunoreactivity using electron microscopy. We found that the occurrence of axon terminals displaying GLT-1 immunoreactivity (GT; Fig. $3 A, B$ ) was significantly lower in cerebral cortex of synGLT-1 KO $(2.3 \pm 0.9 \%)$ compared with controls $[17.3 \pm$ $3.3 \% ; p=0.0029, \mathrm{D}=0.4667, n=30$ ( 3 animals per genotype) $]$. This reduction in GLT-1 immunoreactivity within axon terminals in the synGLT-1 KO is consistent with previous observations in hippocampus of synGLT-1 KO animals (Petr et al., 2015). Almost all excitatory synapses in cerebral cortex of both control $(92 \pm 2 \%)$ and synGLT-1 KO $(96 \pm 1 \%)$ were tripartite, that is, associated with astrocytic processes $[p=0.5860, \mathrm{D}=0.2000, n=$ 30 (3 animals per genotype)]. The proportion of such synaptically associated astrocytic profiles with GLT-1 immunoreactivity (GA; Fig. $3 A, B$ ) was also not significantly different across the two genotype groups [control: $50 \pm 3 \%$; synGLT-1 KO: $65 \pm 5 \%$; $p=$ $0.1344, \mathrm{D}=0.3000, n=30$ ( 3 animals per genotype) , confirming the selectivity of the $\mathrm{KO}$. These data indicate that the formation of the tripartite synapse is not affected, at least at the ultrastructural level, by the absence of GLT-1 in axon terminals in the synGLT-1 KO.

Interestingly, mitochondrial profiles within axon terminals forming excitatory synapses were more prevalent in the synGLT-1 KO (3.0 \pm 0.3 per every group of 10 synapses $)$ compared with controls $[1.8 \pm 0.3 ; p=0.0354, \mathrm{D}=0.3667, n=30(3$ animals per genotype); Fig. $3 C$ ]. Surprisingly, the occurrence of mitochondrial profiles in astrocyte processes associated with excitatory synapses was also significantly elevated in the synGLT-1 KO [1.9 \pm 0.3 mitochondria per every group of 10 synapses vs $0.9 \pm 0.15$ in control; $p=0.0354, \mathrm{D}=0.3667, n=30$ ( 3 animals per genotype); Fig. $3 D$ ]. Presumably, astrocyte processes lacking juxtaposition with excitatory synapses within single planes of section may be associated with excitatory synapses in other planes. Accordingly, the frequency of mitochondrial profiles in astrocytes, both with and without apparent contact to excitatory synapses, per unit area equal to a single micrograph $\left(28.5 \mu \mathrm{m}^{2}\right)$, was also significantly elevated in synGLT- $1 \mathrm{KO}(2.1 \pm 0.2$ per unit area) compared with controls $[0.9 \pm 0.15 ; p=0.0077, \mathrm{D}=$ $0.3478, n=46$ ( 3 animals per genotype); Fig. $3 E$ ].

It has been reported that efficiency of ATP production is related to the density of mitochondrial cristae (Gomes et al., 2011). 


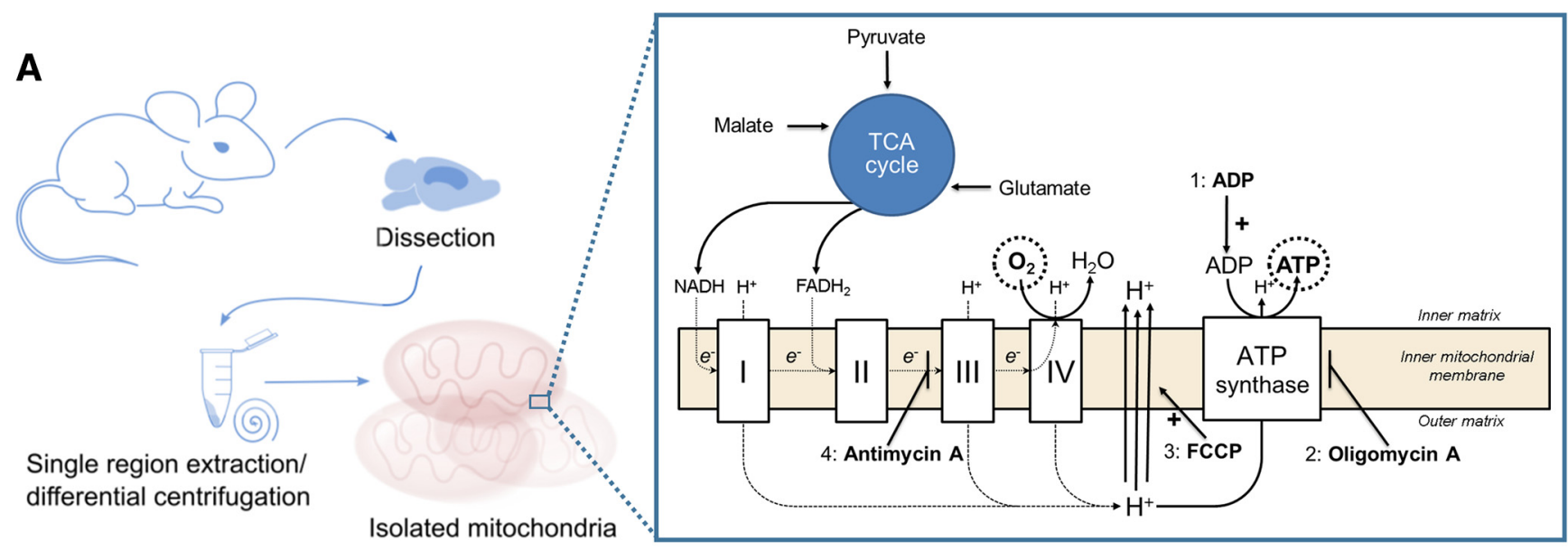

B

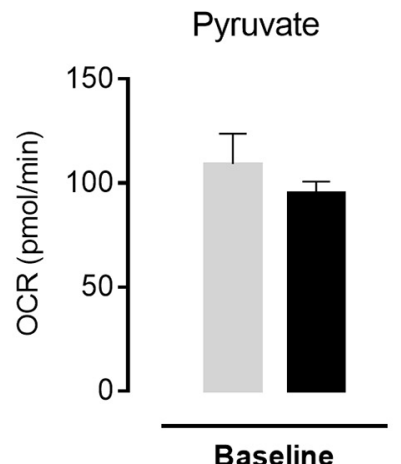

E

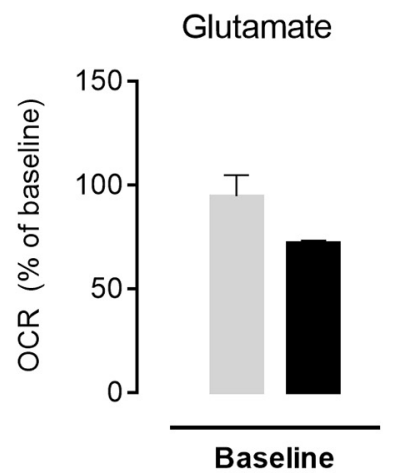

C

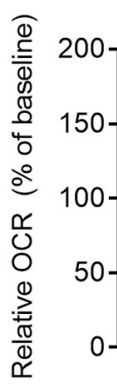

F
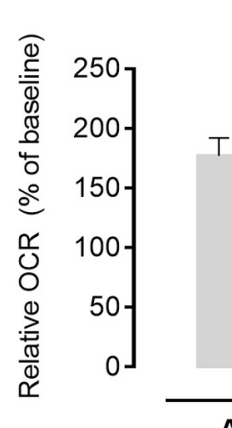

AD
Pyruvate

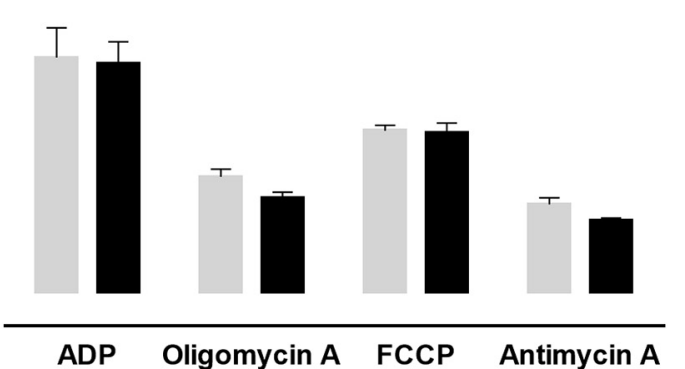

ADP Oligomycin A FCCP Antimycin A
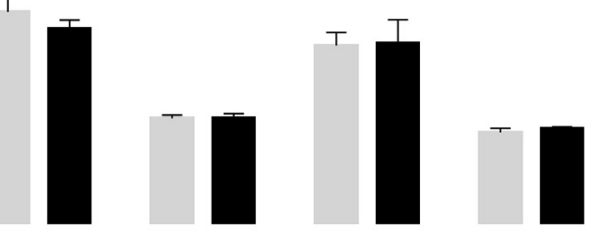

Glutamate

\section{Controls}

D

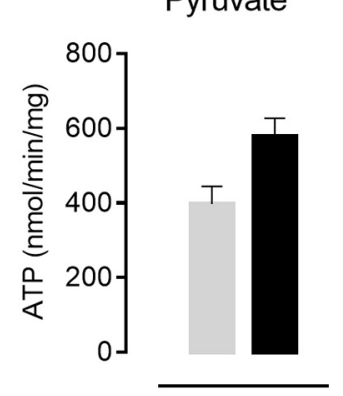

G

Glutamate

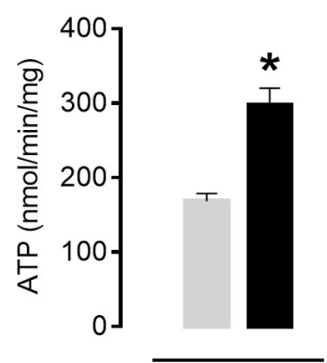

Figure 2. Mitochondria from cerebral cortex of synGLT-1 KO mice exhibit increased ATP production rate and unaffected OCR. A, Mitochondria were isolated from cerebral cortex of mice in which the GLT-1 gene was knocked out in neurons by expression of synapsin-Cre (synGLT-1 KO; black bars) and littermate controls (gray bars). The inner mitochondrial membrane contains complexI-IV and the ATP synthase, comprising the ETC driven by NADH and FADH ${ }_{2}$ output from TCA cycle metabolism. $B, C, E, F$, oxygen consumption was measured in mitochondria in medium containing pyruvate or glutamate, both with malate, in the presence of (1) ADP to stimulate coupled respiration generating ATP, (2) oligomycin A to inhibit ATP synthase, (3) FCCP to induce proton leakage across the mitochondrial membrane leading to maximal uncoupled respiration, and (4) antimycin A to inhibit ETC complex III. D, G, ADP-stimulated ATP production was assayed in mitochondria in medium containing pyruvate or glutamate, both with malate. Data are mean $\pm \operatorname{SEM}(n=3) .{ }^{*} p<0.05$ (Student's $t$ test corrected for multiple comparisons).

Because biochemical assays indicated that synGLT-1 KO leads to increased efficiency in ATP production, we assessed whether synGLT-1 KO also alters the density of mitochondrial cristae. Using the same set of electron micrographs used to analyze the prevalence of mitochondria within axon terminals and astrocytes forming the synaptic tripartite, we assessed the average distance among immediately adjacent cristae at the point of junction to the mitochondrial inner membrane. This measurement revealed a statistically significant genotype difference, with the average distance between cristae being $25 \%$ less for mitochondria sampled from synGLT-1 KO cerebral cortex, relative to control $[79.7 \pm 4.6 \mathrm{~nm}$ vs synGLT-1 KO: $60.5 \pm 2.6 \mathrm{~nm} ; p=0.0013, \mathrm{D}=$ 

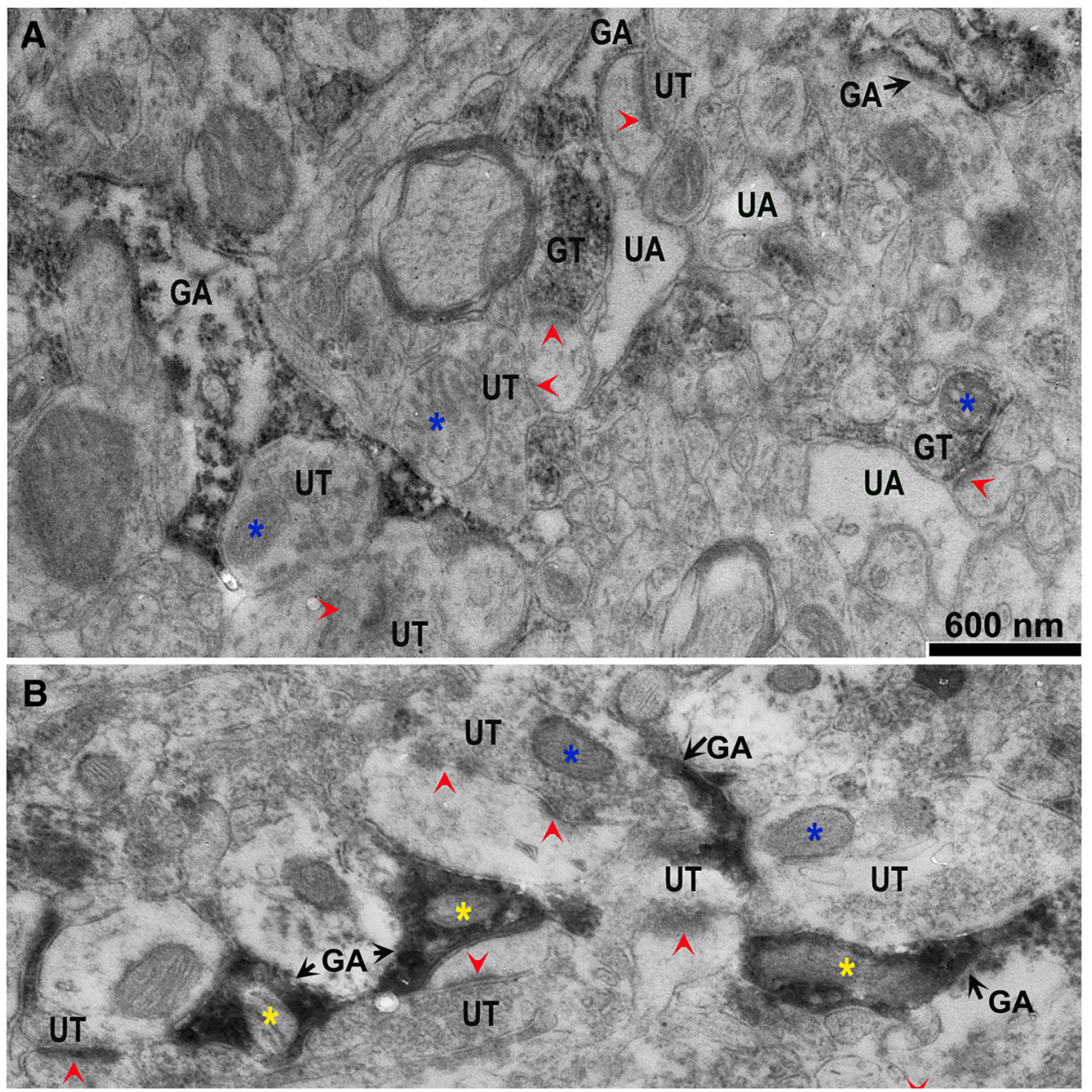

C

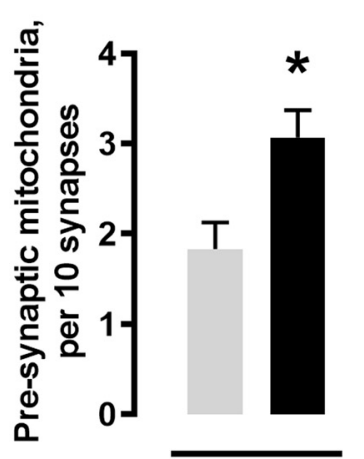

D

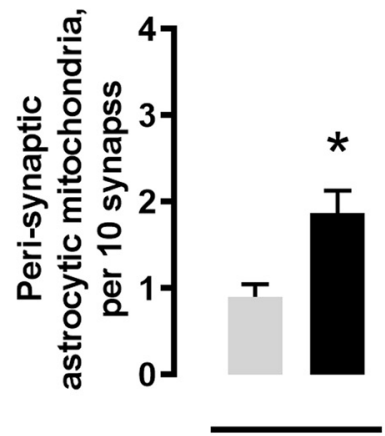

E

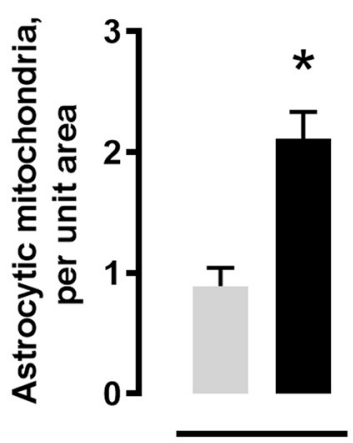

$\mathbf{F}$

\section{Controls}

\section{SynGLT1-1 KO}

Figure 3. Electron microscopy reveals increased occurrence of mitochondrial profiles within astrocytes and excitatory axon terminals and decreased intercristae distance in cerebral cortex of synGLT-1 K0 mice. $\boldsymbol{A}, \boldsymbol{B}$, Representative electron microscopy images from cerebral cortical tissue of mice in which the GLT-1 gene was knocked out in neurons by expression of synapsin-Cre (synGLT-1 $\mathrm{KO} ; \boldsymbol{B})$, and of littermate control mice $(\boldsymbol{A})$. Images were captured at a magnification of 30,000 $\times$. GLT-1 immunoreactivity is evident, based on the electron dense label that is distributed diffusely within the cytoplasm. Both genotypes exhibit GLT-1 immunoreactivity within astrocytes (GA), whereas the presence of immunoreactivity within axon terminals forming asymmetric synapses is more readily apparent within control tissue (GT, $\boldsymbol{A}$ ) than in synGLT-1 KO tissue (none shown in the examples; $\boldsymbol{B}$ ). UA, Astrocytic profiles not exhibiting GLT-1 immunolabeling; UT, axon terminals forming excitatory axo-spinous synapses not exhibiting GLT-1 immunolabeling. Mitochondrial profiles are encountered more frequently within axon terminals forming asymmetric synapses (blue asterisks over mitochondria in $\boldsymbol{A}, \boldsymbol{B}$; red arrowheads point to thick postsynaptic densities; quantified in $\boldsymbol{C}$ ) and astrocytic profiles (yellow asterisks in $\boldsymbol{B}$ and quantified in $\boldsymbol{D}, \boldsymbol{E}$ ) in synGLT-1 K0 tissue than in control tissue. $C$, Relative prevalence of mitochondria in axon terminals forming excitatory synapses, per every group of 10 synapses. $D$, Relative prevalence of mitochondria within astrocytes associated with excitatory synapses, per every group of 10 synapses. $E$, Prevalence of mitochondria within astrocytes, whether or not associated with synapses, per unit area equal to the area spanning one micrograph captured at a magnification of 30,000X.F, Mean distance between neighboring cristae of mitochondria sampled from control and synGLT-1 K0. The numbers of micrographs needed to capture 100 excitatory axo-spinous synaptic profiles were 16,11 , and 19 for the control tissue, totaling 46 micrographs spanning $1311 \mu \mathrm{m}^{2}$, and 18,12 , and 16 micrographs for the synGLT-1 KO tissue, totaling 46 micrographs spanning $1311 \mu \mathrm{m}^{2}$. Gray bars represent controls. Black bars represent synGLT-1 KO. All quantitative results are presented as mean \pm SEM. ${ }^{*} p<$ 0.05 (Kolmogorov-Smirnov). 
A
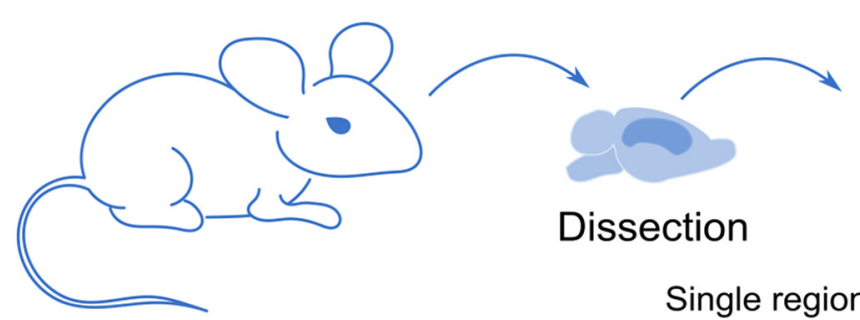

Dissection

Single region extraction/ differential centrifugation

\section{Controls \\ synGLT-1 KO}

B

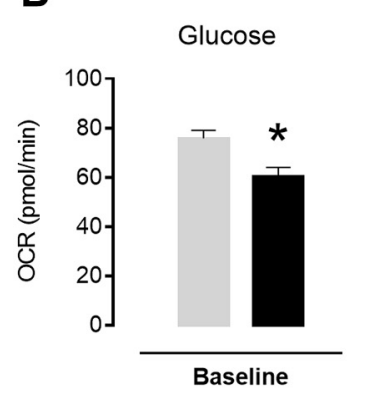

F

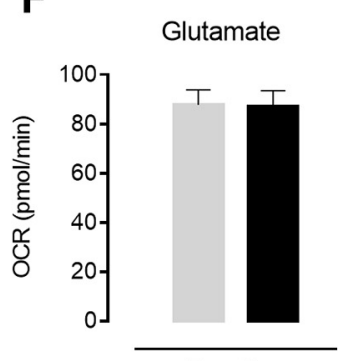

Baseline

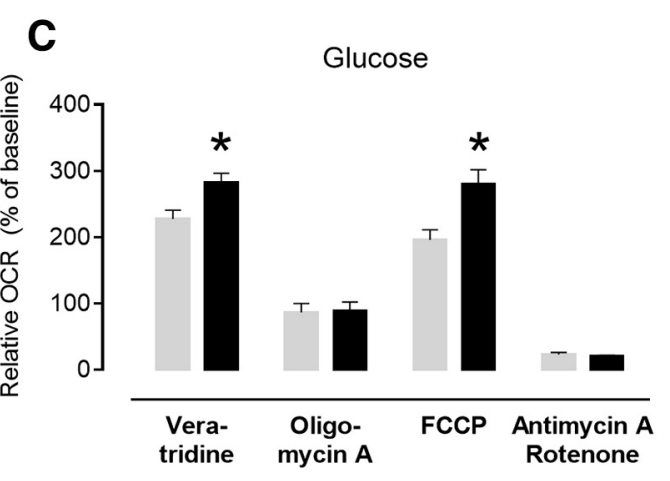

G

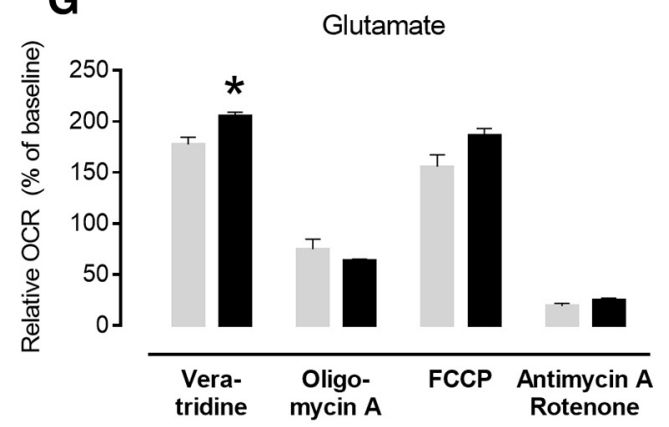

D

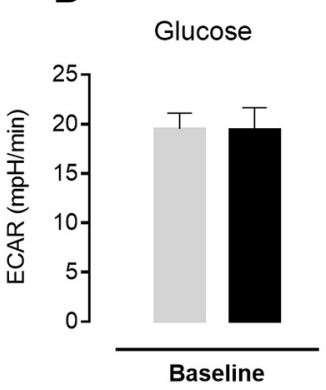

H

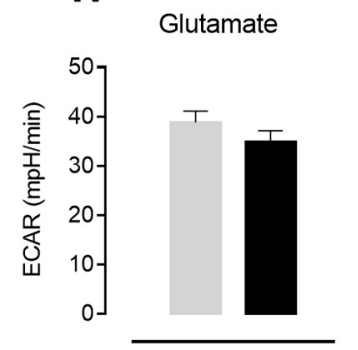

Baseline
E

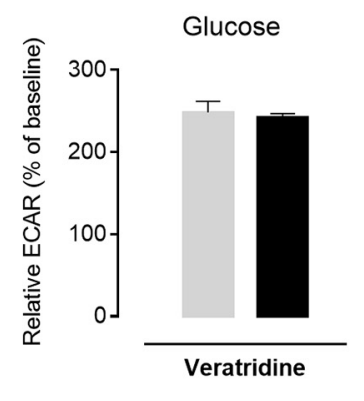

I

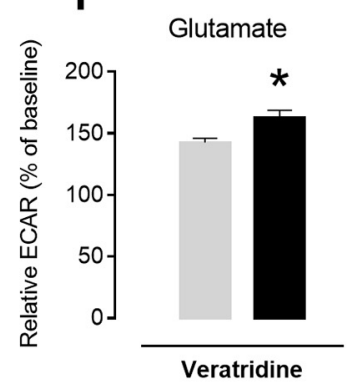

Figure 4. Cerebral cortical synaptosomes of synGLT-1 KO mice display enhanced mitochondrial efficiency and glycolytic activity in the presence of glutamate. $A$, Synaptosomes were isolated from cerebral cortex of mice in which the GLT-1 gene was knocked out in neurons by expression of synapsin-Cre (synGLT-1 K0; black bars) and littermate controls (gray bars). The synaptic OCR and ECAR, the latter being a measure of glycolytic activity, were assessed by Seahorse XFe analysis. The synaptosomes were provided $5 \mathrm{~mm}$ glucose or $5 \mathrm{~mm}$ glucose supplemented with $0.1 \mathrm{~mm}$ glutamate as respiratory substrates. Respiration and glycolytic activity were stimulated and inhibited by sequential addition of (1) veratridine inhibiting sodium channel inactivation leading to synaptic depolarization, (2) oligomycin A inhibiting the ATP synthase, (3) FCCP leading to uncoupled respiration, and (4) antimycin A in combination with rotenone to inhibit complex III and I of the ETC, respectively. Because veratridine induces maximal glycolytic activity, only ECAR for this injection is reported. $\boldsymbol{B}-\boldsymbol{E}$, Synaptosomal OCR and ECAR were determined with glucose as only respiratory substrate under both resting $(\boldsymbol{B}, \boldsymbol{D})$ and stimulated $(\boldsymbol{C}, \boldsymbol{E})$ conditions. $\boldsymbol{F}-\boldsymbol{I}$, Synaptosomal $0 C R$ and ECAR were also assessed in the presence of glutamate, in addition to glucose, again under both resting $(\boldsymbol{F}, \boldsymbol{H})$ and stimulated $(\boldsymbol{G}, \boldsymbol{I})$ conditions. Data are mean \pm SEM $(n=5) .{ }^{*} p<0.05$ (Student's $t$ test corrected for multiple comparisons).

$0.3500, n=20$ (3 animals per genotype); Fig. $3 F]$. These values indicate that cristae of mitochondria of synGLT-1 KO cerebral cortex are packed more closely to one another, enabling greater efficiency of ATP production.

Together, these EM data are consistent with the hypothesis that the operation of neuronal GLT-1 is linked to the function of mitochondria within axon terminals and astrocytic processes forming tripartite synapses.

\section{Synaptosomal glutamate uptake and metabolism}

Oxygen consumption and glycolytic activity

In view of the results suggesting elevated mitochondrial efficiency (increased rate of ATP production, increased cristae density) and increased occurrence of mitochondria in presynaptic terminals, we next sought to investigate neuronal metabolism more specifically. Whereas isolated mitochondria represent a multicellular preparation, in which effects of the $\mathrm{KO}$ on neurons may be masked by a larger contribution from mitochondria from other cells, we chose to further investigate metabolism in synaptosomes, which primarily represent the neuronal compartment of the source tissue (Fig. 4A).

First, the OCR was determined in synaptosomes from synGLT-1 KO and control mice. In the presence of glucose as respiratory substrate, basal respiration was significantly decreased in the synGLT-1 KO (by $\sim 20 \%, t_{(8)}=3.218, p=0.0123$, $n=5$; Fig. $4 B$ ). This could either indicate a lower metabolic capacity of the synGLT-1 KO or that the synaptosomes of the synGLT-1 KO consume less oxygen during resting conditions (i.e., enhanced mitochondrial efficiency). In the presence of glutamate, in addition to glucose, no difference in baseline respiration was observed for the synGLT-1 KO $\left(_{(8)}=0.0084, p=0.935\right.$, 
$n=5$; Fig. $4 F$ ), showing that the addition of glutamate stimulates baseline respiration of the synGLT-1 KO to a level similar to the control. This could indicate a stronger metabolic response to the presence of glutamate in the KO preparation, and may suggest improved mitochondrial efficiency as an explanation of the observed lower baseline respiration in the presence of glucose alone. It may seem at first glance paradoxical that the synGLT-1 KO synaptosomes can respond metabolically to extracellular glutamate. However, it is known that the neuronal $\mathrm{KO}$ achieved using synapsin-Cre is incomplete (Taugher et al., 2017; Zhou et al., 2019), which may be, in part, the explanation for the observation that the reduction of glutamate uptake into synaptosomes is only 40\%-50\% (Petr et al., 2015; Danbolt et al., 2016; Rimmele and Rosenberg, 2016; Zhou et al., 2019).

When the synaptosomes were challenged with veratridine or uncoupled with FCCP, in the presence of glucose alone, the relative OCR was significantly increased for the synGLT-1 KO (veratridine: $\sim 24 \%, t_{(8)}=2.873, p=0.0219, n=5$; FCCP: by $\sim 43 \%, t_{(8)}=3.158, p=0.0134, n=5$; Fig. $4 C$ ). In the presence of glutamate, in addition to glucose, veratridine stimulation gave rise to a significant increase in OCR (by $\sim 16 \%, t_{(8)}=3.56, p=$ $0.0074, n=5$ ), and a tendency toward an increase was observed in the presence of FCCP $\left(t_{(8)}=2.21, p=0.0585, n=5\right.$; Fig. $\left.4 G\right)$. No changes in OCR were observed in the presence of oligomycin A (glucose: $t_{(8)}=0.1315, p=0899$; glutamate: $t_{(8)}=1.158, p=$ $0.280, n=5)$ or antimycin A in combination with rotenone (glucose: $t_{(8)}=0.7875, p=0.454$; glutamate: $t_{(8)}=1.758, p=$ $0.117, n=5$; Fig. $4 C, G)$. Collectively, these data are consistent with the view that the synGLT-1 KO has increased mitochondrial capacity.

In parallel, the ECAR was determined as a measure of glycolytic activity. With glucose as the only substrate, no changes in ECAR were observed during resting conditions $\left(t_{(8)}=0.032, p=\right.$ $0.975, n=5$; Fig. $4 D$ ) or following stimulation with veratridine $\left(t_{(8)}=0.456, p=0.661, n=5\right.$; Fig. $\left.4 E\right)$. Similarly, baseline glycolytic activity was unchanged in the synGLT-1 KO in the presence of glutamate $\left(t_{(8)}=1.22, p=0.257, n=5\right.$; Fig. $4 H$ ), whereas veratridine stimulation led to a significantly elevated glycolytic activity (by $\sim 14 \%, t_{(8)}=2.70, p=0.0270, n=5$; Fig. $4 I$ ), suggesting that glutamate elevates glycolytic activity in the synGLT-1 KO.

Together, these data support our conclusion that GLT-1 expressed in neurons is important for neuronal mitochondrial function, and that operation of GLT-1 in neurons modulates neuronal glycolytic activity.

\section{Glutamate uptake}

Previously published studies reported that conditional deletion of GLT-1 in neurons using synapsin-Cre resulted in a $40 \%$ loss of glutamate uptake in crude synaptosomes from the whole forebrain (Petr et al., 2015). We wanted to ascertain whether a similar deficit in glutamate uptake could be demonstrated in synaptosomes isolated from the cerebral cortex. We found that glutamate uptake was significantly reduced in cerebral cortical synaptosomes from synGLT-1 KO (reduced by $\sim 50 \%, t_{(10)}=2.54, p=$ $0.029, n=6$; Fig. $5 A$ ). This is in remarkable agreement with recently published results, also obtained in cerebral cortex using a different conditional GLT-1 KO mouse (Zhou et al., 2019).

\section{Total metabolite concentrations}

To dissect out the effects of synGLT-1 KO specifically on synaptic metabolism, concentrations of metabolites were determined in purified synaptosomes of cerebral cortex using HPLC. The incubation media contained $2.5 \mathrm{~mm}$ glucose with addition of $0.1 \mathrm{~mm}$ glutamate to provide substrate for GLT-1 and further metabolism. Total aspartate levels were significantly lower [by $\sim 25 \%$, $t_{(15)}=2.378, p=0.031, n=7-10$ ( 4 or 5 animals per genotype); Fig. $5 B]$ in synaptosomes from synGLT-1 KO mice. This finding is consistent with the previously mentioned in vivo observations (Fig. 1) and confirms involvement, specifically, of neuronal GLT-1 in aspartate homeostasis. As found for whole region extracts of cerebral cortex, no significant differences were observed for synaptosome glutamate levels [synGLT-1 KO: $46 \pm 5$ vs control: $43 \pm 3 \mathrm{nmol} / \mathrm{mg}$ protein, $t_{(15)}=0.5945, p=0.561, n=7-10$ (4 or 5 animals per genotype)], nor the majority of remaining metabolites measured (glutamine, serine, valine, isoleucine, and leucine; $p>0.05$; individual $p$ values reported in Table 2), except alanine, which was elevated (synGLT-1 KO: $2.63 \pm 0.07$ vs control: $2.32 \pm 0.06 \mathrm{nmol} / \mathrm{mg}$ protein, $t_{(13)}=3.227, p=0.007, n=$ $6-8)$.

\section{Glutamate metabolism}

Purified synaptosomes from cerebral cortex of synGLT-1 KO animals incubated for $1 \mathrm{~h}$ in medium containing unlabeled glucose and $\left[\mathrm{U}-{ }^{13} \mathrm{C}\right]$-glutamate $(\mathrm{M}+5)$ exhibited $\sim 20 \%$ lower intracellular glutamate $\mathrm{M}+5$ labeling $\left(t_{(7)}=2.457, p=0.044, n=\right.$ 4 or 5; Fig. $5 C$ ), consistent with a loss of functional glutamate transporters in axon terminals in the synGLT-1 KO. From the experiments measuring glutamate uptake as well as those investigating $\left[\mathrm{U}-{ }^{13} \mathrm{C}\right]$ glutamate metabolism, we observed a residual glutamate uptake which is likely caused by a less than complete excision mediated by synapsin-Cre in neurons, as has been demonstrated previously (Taugher et al., 2017; Zhou et al., 2019). The difference between the reduction in glutamate uptake and the reduction in glutamate $\mathrm{M}+5$ labeling is likely due to the different conditions of the two experiments.

${ }^{13} \mathrm{C}$ labeling of the TCA cycle intermediates citrate and malate, and the amino acid aspartate, was decreased to an extent similar to that of glutamate $\left(n=4\right.$ or 5 , citrate: $t_{(7)}=3.131, p=0.017$; malate: $t_{(7)}=1.666, p=0.140$; aspartate: $t_{(7)}=3.017, p=0.019$; Fig. $5 C$ ), supporting the hypothesis that glutamate taken up via GLT-1 expressed in presynaptic terminals is a substrate for synaptic TCA cycle metabolism and provision of energy.

\section{Aspartate production and pyruvate recycling}

We observed decreased amounts of aspartate in the cerebral cortex of synGLT-1 KO in both the in vivo and the synaptosome experiments described above, suggesting a lower aspartate production and/or higher aspartate consumption induced by the KO of GLT-1 in neurons. To assess these two possibilities, the aspartate production rate was calculated as [aspartate $\mathrm{M}+4] /[$ malate $\mathrm{M}+4] \times[$ aspartate amount], using total amounts determined by HPLC and percentage ${ }^{13} \mathrm{C}$ labeling from GC-MS measurements on synaptosomes incubated with $\left[\mathrm{U}_{-}{ }^{13} \mathrm{C}\right]$ glutamate (calculation principle adapted from Morken et al., 2014). Aspartate is produced from OAA; however, the pool of OAA is too small for MS detection. Because the pools of the TCA cycle intermediates OAA and malate are in equilibrium, malate ${ }^{13} \mathrm{C}$ labeling was used as a measure of $\mathrm{OAA}{ }^{13} \mathrm{C}$ labeling. The production rate calculated from data derived from synaptosomes of the synGLT-1 KO animals was $\sim 41 \%$ lower than the rate calculated from data obtained from control animals $\left(t_{(7)}=3.332, p=0.01, n=4\right.$ or 5 ; Fig. 6A). Similarly, aspartate production resulting from glutamate entry into the TCA cycle can be estimated using glutamate 
A

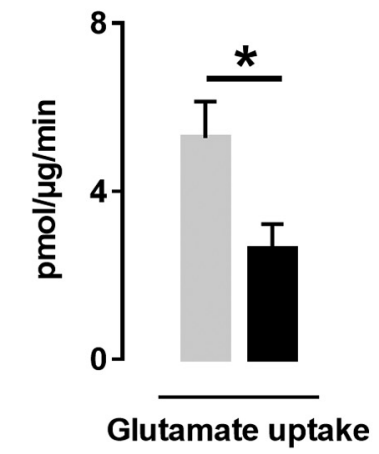

B

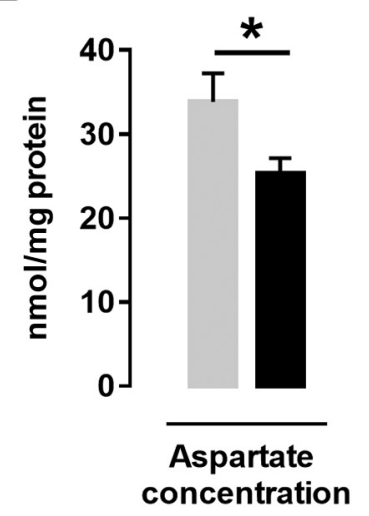

C

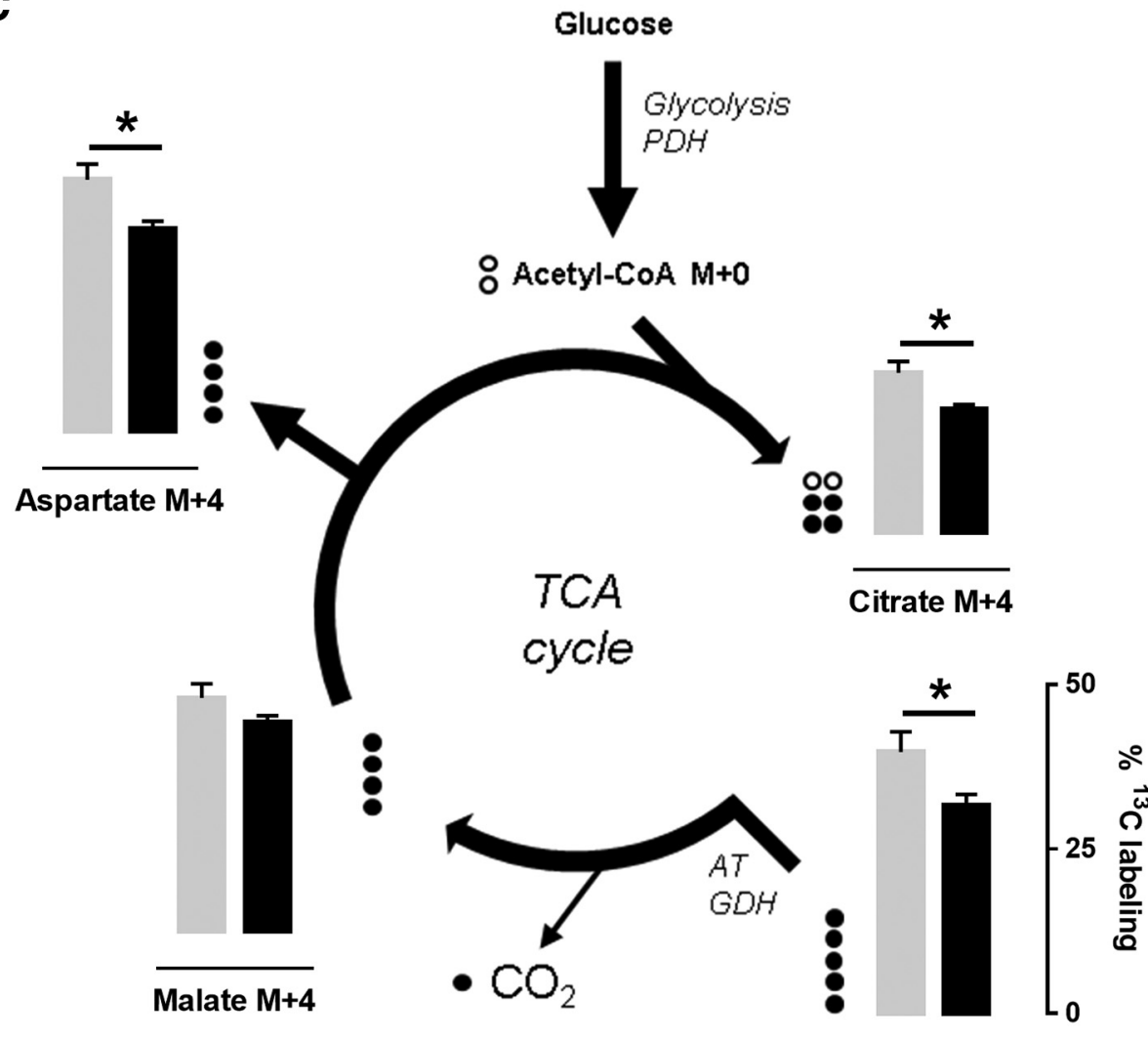

Glutamate $M+5$

\section{Controls synGLT-1 KO}

Figure 5. Synaptosomal glutamate metabolism is altered in cerebral cortex of synGLT-1 K0 mice. Synaptosomes were purified from cerebral cortex of mice in which the GLT-1 gene was knocked out in neurons by expression of synapsin-Cre (synGLT-1 K0; black bars) and littermate controls (gray bars). $\boldsymbol{A}$, Glutamate uptake into crude synaptosomes from synGLT-1 K0 and controls was determined using L $\left[{ }^{3} \mathrm{H}\right]$-glutamate $(n=6) . \mathbf{B}, \mathbf{C}$, Synaptic metabolism was assessed by incubating $45 \mathrm{~min}$ with $2.5 \mathrm{~mm}$ unlabeled glucose in combination with $0.1 \mathrm{~mm}\left[\mathrm{U}-{ }^{13} \mathrm{C}\right]-$ glutamate $(\mathrm{M}+5)$ before determination of total metabolite concentrations by $\operatorname{HPCC}(\boldsymbol{B}$; and Table $2 ; n=8-10)$ and percentage ${ }^{13} \mathrm{Clabeling}$ in metabolites by GC-MS $(\boldsymbol{C} ; n=4$ or 5$)$. $\boldsymbol{C}$, Black and white circles represent ${ }^{13} \mathrm{C}$ and ${ }^{12} \mathrm{C}$, respectively. PDH, Pyruvate dehydrogenase; AT, aminotransferase. Data are mean \pm SEM. ${ }^{*} p<0.05$ (Student's $t$ test corrected for multiple comparisons).

Table 2. Total amino acid concentrations ( $\mathrm{nmol} / \mathrm{mg}$ protein) in extracts of cerebral cortical synaptosomes determined by HPLC ${ }^{a}$

\begin{tabular}{lllrl}
\hline Metabolite & Control & synGLT-1 K0 & \multicolumn{1}{c}{$t(\mathrm{df})$} & $p$ \\
\hline Alanine & $2.32 \pm 0.06$ & $2.63 \pm 0.07$ & $3.227(13)$ & 0.007 \\
Glutamate & $46.2 \pm 5.22$ & $42.9 \pm 3.48$ & $0.5946(15)$ & 0.561 \\
Glutamine & $3.66 \pm 0.44$ & $3.32 \pm 0.33$ & $0.6301(15)$ & 0.538 \\
Isoleucine & $2.99 \pm 0.31$ & $2.74 \pm 0.19$ & $0.726(15)$ & 0.479 \\
Leucine & $2.90 \pm 0.26$ & $2.71 \pm 0.17$ & $0.6415(15)$ & 0.531 \\
Serine & $3.20 \pm 0.29$ & $3.12 \pm 0.20$ & $0.2406(15)$ & 0.813 \\
Valine & $3.03 \pm 0.42$ & $2.83 \pm 0.34$ & $0.3541(15)$ & 0.728
\end{tabular}

${ }^{a}$ This table summarizes concentrations of total (labeled and unlabeled) metabolites in extracts of synaptosomes prepared from cerebral cortex obtained by HPLC. No significant differences were found in the concentrations of any metabolite measured, excluding aspartate (see Fig. 5) and alanine. Results are presented as mean $\pm \mathrm{SEM} ; n=$ 7-10 preparations (from 4 control or 5 synGLT-1 KO mice).

\footnotetext{
${ }^{13} \mathrm{C}$ labeling ([aspartate $\left.\mathrm{M}+4\right] /[$ glutamate $\mathrm{M}+5] \times$ [aspartate amount]). A significant reduction of similar magnitude was estimated using this equation $(23 \pm 5$ in $\mathrm{KO}$ vs $38 \pm 9$ $\mathrm{nmol} / \mathrm{mg}$ protein/h in control; $\left.t_{(7)}=2.473, p=0.043\right)$. These results suggest that the lower aspartate concentration measured in synGLT-1 KO tissue in vivo and in synaptosomes is likely due to decreased aspartate production. Given the evidence that glutamate taken up by GLT-1 in neurons is metabolized in the TCA cycle, we hypothesize that glutamate can
}

increase the TCA cycle intermediate pool (anaplerosis) and promote production of aspartate. When anaplerosis from glutamate is reduced by $\mathrm{KO}$ of GLT-1 in axon terminals, aspartate production is decreased.

Reduced anaplerosis is expected to be paralleled by reduced cataplerosis to maintain carbon homeostasis (Sonnewald, 2014). Pyruvate recycling entails full oxidation of glutamate and is the main cataplerotic pathway related to TCA cycle metabolism. The pathway consists of the conversion of malate to pyruvate via malic enzyme, followed by pyruvate dehydrogenase-mediated formation of acetyl-CoA, which finally reenters the TCA cycle by condensation with OAA to form citrate (Fig. 6C). As accounted for previously (Nissen et al., 2015), a measure of pyruvate recycling can be derived from ${ }^{13} \mathrm{C}$ labeling data obtained from incubation with $\left[\mathrm{U}_{-}{ }^{13} \mathrm{C}\right]$ glutamate (e.g., citrate $\mathrm{M}+6$ ). To account for the difference in entry of ${ }^{13} \mathrm{C}$ labeling from glutamate into the TCA cycle in the synGLT-1 KO and control, the ratio between citrate $M+6$ and malate $M+4$ was used. As predicted, this ratio was significantly reduced by $\sim 35 \%$ in the synGLT-1 KO $\left(t_{(7)}=\right.$ 2.564, $p=0.037, n=4$ or 5 ; Fig. $6 B$ ), suggesting that the metabolic machinery supporting cataplerosis is reduced in response to synGLT-1 KO. Therefore, GLT-1 in neurons, specifically GLT-1 expressed in axon terminals, appears to supply glutamate for support of synaptic TCA cycle metabolism. 


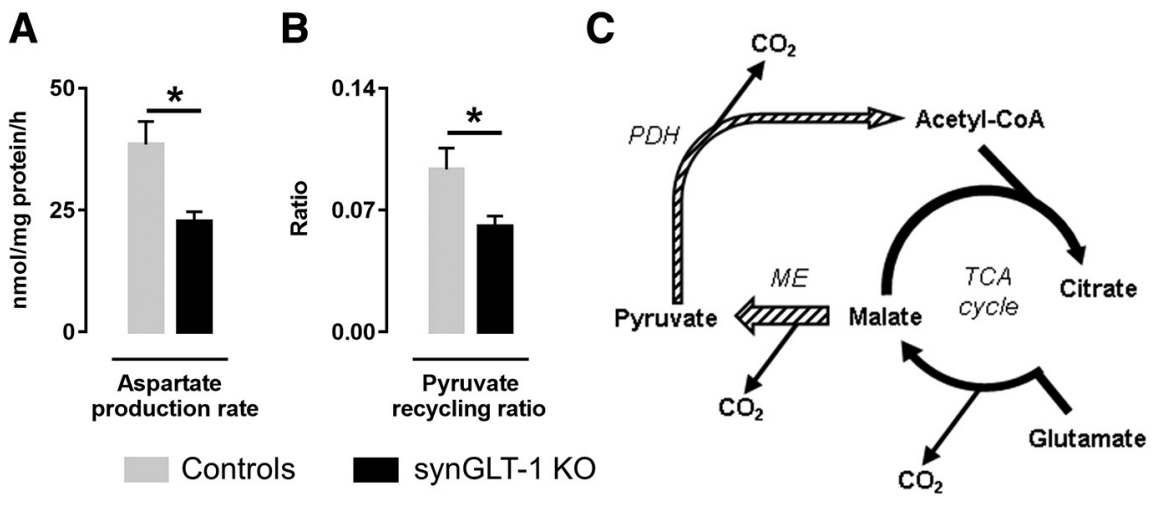

Figure 6. Aspartate production and pyruvate recycling are reduced in synaptosomes from cerebral cortex of synGLT-1 mice. Synaptosomes were purified from cerebral cortex of mice in which the GLT-1 gene was knocked out in neurons by expression of synapsin-Cre (synGLT-1 K0; black bars) and littermate controls (gray bars). Synaptic metabolism was assessed by incubating 45 min with $2.5 \mathrm{~mm}$ unlabeled glucose in combination with $0.1 \mathrm{~mm}\left[\mathrm{U}-{ }^{13} \mathrm{C}\right]$-glutamate $(\mathrm{M}+5)$. $\boldsymbol{A}$, The aspartate production rate was calculated as [aspartate $\mathrm{M}+4] /[$ malate $\mathrm{M}+4) \times$ [aspartate] using total concentration (nmol/mg protein) of aspartate and percentage ${ }^{13} \mathrm{C}$ labeling in metabolites obtained from HPLC and GC-MS analysis, respectively $(n=4$ or 5$)$. $\boldsymbol{B}, \boldsymbol{C}$, The pyruvate recycling pathway entails: entry of glutamate into TCA cycle metabolism, synthesis of pyruvate from malate by malic enzyme (ME), and reentry into TCA cycle metabolism as acetyl-CoA produced by pyruvate dehydrogenase (PDH). The ratio [citrate $M+6] /[$ malate $\mathrm{M}+4]$ is used as an estimation of pyruvate recycling activity. Data are mean \pm SEM. $^{*} p<0.05$ (Student's $t$ test corrected for multiple comparisons).

\section{Glycolytic activity}

Our previously mentioned observations suggested that synGLT-1 $\mathrm{KO}$ affects synaptosomal glycolytic activity. Therefore, to further assess the effect of synGLT-1 KO on glycolytic activity as well as to provide a secondary measure of the effects on TCA cycle metabolism, we next incubated cerebral cortical synaptosomes with $\left[\mathrm{U}-{ }^{13} \mathrm{C}\right]$-glucose in the presence of unlabeled glutamate. Breakdown of $\left[\mathrm{U}-{ }^{13} \mathrm{C}\right]$-glucose to $\left[\mathrm{U}-{ }^{13} \mathrm{C}\right]$-pyruvate via glycolysis and subsequent action of $\mathrm{LDH}$ or alanine aminotransferase will lead to the formation of $\left[\mathrm{U}-{ }^{13} \mathrm{C}\right]$-lactate and $\left[\mathrm{U}-{ }^{13} \mathrm{C}\right]$-alanine $(\mathrm{M}+3)$, respectively. Hence, the percentage lactate $\mathrm{M}+3$ and alanine $\mathrm{M}+3$ in synaptosomal preparations incubated with $\left[\mathrm{U}-{ }^{13} \mathrm{C}\right]-$ glucose are indicators of glycolytic activity.

In the presence of $\left[\mathrm{U}_{-}{ }^{13} \mathrm{C}\right]$-glucose and unlabeled glutamate, total lactate amounts in medium and extracts of cerebral cortical synaptosomes from synGLT-1 KO mice were unchanged [medium: $t_{(15)}=0.7888, p=0.442$; extract: $t_{(14)}=0.3778, p=0.711$; $n=6-8$ (from 4 or 5 animals per genotype); Fig. 7A]. In contrast, an $\sim 150 \%$ higher percentage lactate $M+3$ labeling was observed in synaptosome extracts $\left(t_{(7)}=2.445, p=0.044, n=4\right.$ or 5$)$, and a similar trend was observed for alanine $\mathrm{M}+3$ in synaptosome extracts $\left(t_{(7)}=2.038, p=0.081, n=4\right.$ or 5; Fig. $\left.7 B\right)$. Furthermore, an approximate $30 \%$ increase was observed for alanine $\mathrm{M}+3$ in the medium $\left(t_{(7)}=3.702, p=0.008, n=4\right.$ or 5$)$, which is in accordance with the observed increased intracellular amount of alanine in synaptosomes of the synGLT-1 KO. An increase in lactate $\mathrm{M}+3$ in the medium was not observed $\left(t_{(7)}=0.203, p=\right.$ $0.845 n=4$ or 5; Fig. $7 B$ ). Collectively, these data provide additional evidence that the cerebral cortex of synGLT-1 KO mice can exhibit higher glycolytic activity in the presence of glutamate as observed from the assessment of glycolytic activity using the Seahorse XFe assay measuring ECAR.

\section{TCA cycle metabolism}

Incubation of cerebral cortical synaptosomes with $\left[\mathrm{U}_{-}{ }^{13} \mathrm{C}\right]-$ glucose will result in an influx of ${ }^{13} \mathrm{C}$ into the TCA cycle intermediate pool, whereas unlabeled glutamate can provide an influx of unlabeled carbon into the TCA cycle intermediate pool (Fig. $7 C$ ). KO of neuronal GLT-1 reduces input of unlabeled glutamate into the TCA cycle. In turn, this will lead to decreased formation of unlabeled OAA, diminishing the probability of unlabeled OAA condensing with acetyl-CoA $\mathrm{M}+2$ to form citrate $\mathrm{M}+2$. We hypothesized that the synGLT-1 KO would introduce decreased percentage $\mathrm{M}+2$ and increased percentages for the remaining isotopologs $(\mathrm{M}+1, \mathrm{M}+3$, etc. $)$ in TCA cycle intermediates derived from consecutive TCA cycle metabolism (for further details, see Walls et al., 2014). Indeed, the ratio between $\mathrm{M}+2$ and the sum of the remaining isotopologs, designated "unlabeled TCA cycle intermediate input," was significantly reduced for malate, citrate, glutamate, and aspartate in the synGLT-1 KO (malate: $t_{(7)}=3.381, p=0.012$; citrate: $t_{(7)}=2.922, p=0.022$; glutamate: $t_{(7)}=$ 3.034, $p=0.019$; aspartate: $t_{(7)}=4.39$, $p=0.003, n=4$ or 5 ; Fig. $7 D)$. These results using $\left[\mathrm{U}-{ }^{13} \mathrm{C}\right]$-glucose as labeled substrate confirm our previous conclusion from data obtained with $\left[\mathrm{U}_{-}{ }^{13} \mathrm{C}\right]-$ glutamate as precursor (Fig. 5; i.e., that glutamate taken up via GLT-1 in axon terminals is metabolized by the mitochondria in those terminals).

\section{Discussion}

In this study, we used a conditional KO of GLT-1 in neurons to understand how this glutamate transporter contributes to neuronal metabolism. ${ }^{1} \mathrm{H}-\mathrm{NMR}$ spectroscopy revealed a significantly reduced aspartate concentration in cerebral cortex of synGLT-1 KO mice. Assays of oxygen consumption and ATP production in mitochondria isolated from cerebral cortex to further investigate the mitochondrial machinery revealed increased ATP production and unchanged oxygen consumption in synGLT-1 KO cerebral cortex. Electron microscopy demonstrated significantly increased mitochondrial density in neurons and perisynaptic astrocyte processes as well as increased cristae density in synaptic mitochondria in the synGLT-1 KO providing a separate line of evidence suggesting the importance of neuronal GLT-1 expression for mitochondrial function. Assessment of oxygen consumption, glycolytic activity, glutamate uptake, and metabolic ${ }^{13} \mathrm{C}$ labeling experiments in synaptosomes from cerebral cortex to identify changes specific to synapses confirmed the expected decrease in GLT-1-mediated glutamate uptake in cerebral cortical synaptosomes from synGLT-1 KO animals, and strongly linked GLT-1 expressed in axon terminals to synaptic glycolytic activity and mitochondrial TCA cycle metabolism.

\section{Glutamate homeostasis relies on neuronal GLT-1 expression}

The current in vivo experiments revealed lower aspartate levels in extracts of cerebral cortex from synGLT-1 KO mice. The concentrations of excitatory amino acids glutamate and aspartate are both known to be significantly higher in neurons compared with astrocytes (Ottersen and Storm-Mathisen, 1984, 1985; StormMathisen et al., 1992; Ottersen et al., 1996), and so changes in aspartate found in tissue extracts are likely to reflect neuronal changes in response to synGLT-1 KO. The in vivo findings are supported by the observation of decreased aspartate levels in purified synaptosomes from the synGLT-1 KO, and together suggest that neuronal GLT-1 is involved in maintaining neuronal 
A

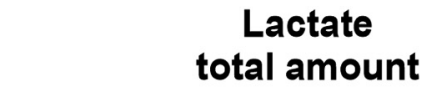

C

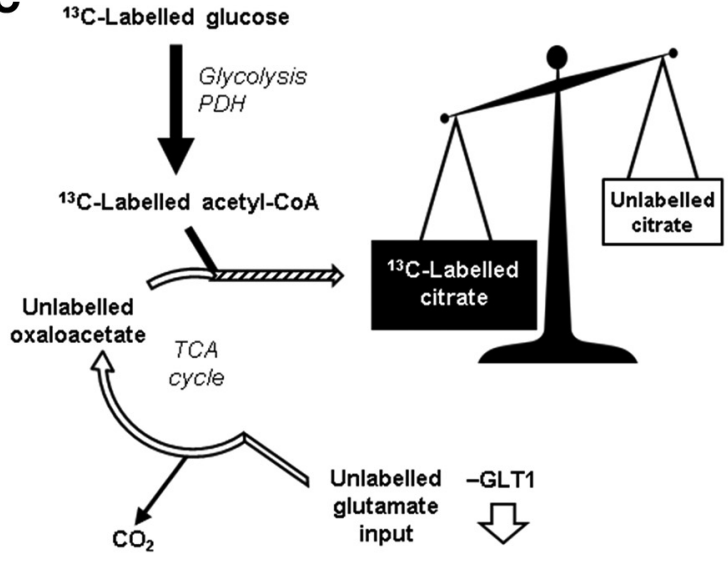

B

Lactate $M+3$

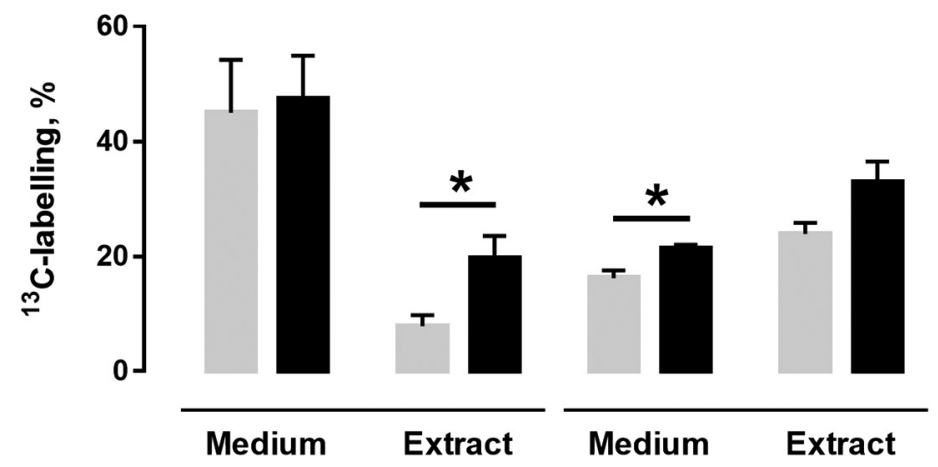

D

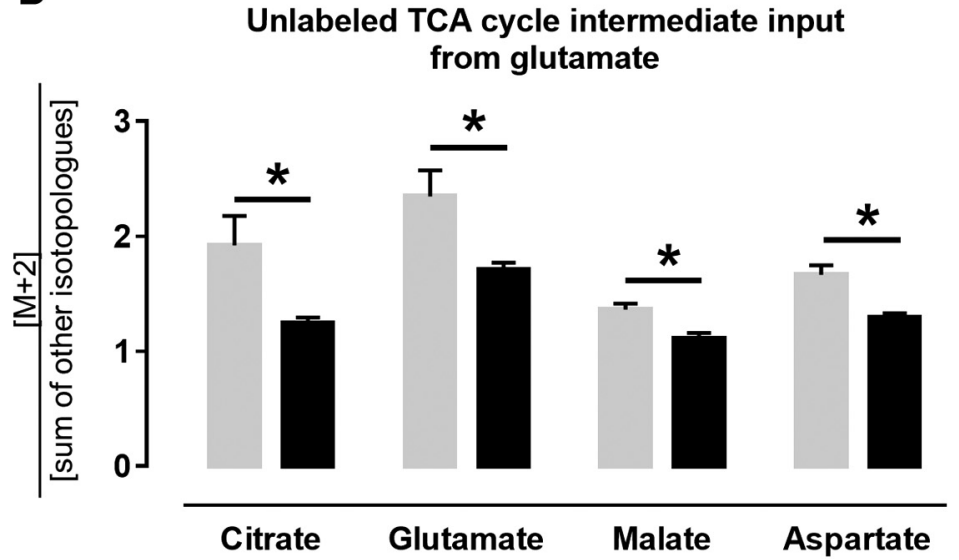

\section{Controls synGLT-1 KO}

Figure 7. Glycolysis and glutamate metabolism is altered in cerebral cortical synaptosomes from synGLT-1 KO mice. Synaptosomes were purified from cerebral cortex of mice in which the GLT-1 gene was knocked out in neurons by expression of synapsin-Cre (synGLT-1 KO; black bars) and littermate controls (gray bars). Synaptic metabolism was assessed by incubating 45 min with $2.5 \mathrm{~mm}$ $\left[\mathrm{U}-{ }^{13} \mathrm{C}\right]$ glucose in combination with $0.1 \mathrm{~mm}$ unlabeled glutamate. Metabolism of glucose via glycolysis gives rise to pyruvate, which can be metabolized to acetyl-CoA via pyruvate dehydrogenase $(\mathrm{PDH})$, alanine via alanine aminotransferase, or lactate via lactate dehydrogenase. $\boldsymbol{A}$, Total lactate concentrations and $(\boldsymbol{B})$ percentage ${ }^{13} \mathrm{C}$ labeling in lactate and alanine were determined in synaptosome extracts and the incubation medium ( $n=4$ or 5). C, D, Metabolism of $\left[U-{ }_{-13}^{13} \mathrm{C}\right]$-glucose gives rise to ${ }^{13} \mathrm{Clabeling}$ in TCA cycle intermediates and amino acids derived thereof (e.g., $\mathrm{c}$ itrate, malate, glutamate, and aspartate). Entry of unlabeled glutamate (taken up by neurons via GLT-1) will increase the unlabeled pool of TCA cycle intermediates. This entry of unlabeled glutamate was assessed as the ratio $[M+2] /\left[\right.$ sum of other isotopologs] for the metabolites citrate, glutamate, malate, and aspartate. Data are mean \pm SEM. ${ }^{*} p<0.05$ (Student's $t$ test corrected for multiple comparisons).

aspartate homeostasis. Comparison of aspartate production rates in the synGLT-1 KO and controls indicate reduced aspartate production in the synGLT-1 KO. Moreover, we found a decline in pyruvate recycling, a cataplerotic pathway required for full oxidation of glutamate. These findings indicate that the metabolic pathways supporting aspartate production and pyruvate recycling are suppressed in the synGLT-1 KO. These changes are likely to be consequences of limited glutamate availability in the synapse and further suggest that glutamate taken up by GLT-1 in axon terminals has an anaplerotic function that supports the TCA cycle intermediate pool and the production of aspartate. In agreement with this hypothesis, synaptosomes obtained from mice in which glutamate dehydrogenase, converting glutamate to $\alpha$-ketoglutarate, is deleted, exhibit decreased aspartate levels (Hohnholt et al., 2018). TCA cycle metabolism is a requirement for de novo aspartate synthesis from glutamate (i.e., the truncated TCA cycle) (Nissen et al., 2015). Our data support the signifi- cance of the truncated TCA cycle producing aspartate from glutamate in neurons.

Aspartate has been suggested to provide the amino group for glutamine formation in astrocytes (Pardo et al., 2011), thereby potentially supporting neuronal glutamate formation following astrocyte-neuron glutamine transfer. Hence, it is possible that the decreased aspartate levels are caused by elevated aspartate consumption and glutamine production to compensate for decreased neuronal glutamate uptake and reuse. This would, however, entail simultaneous increase in astrocyte-neuron glutamine transfer, which based on the in vivo ${ }^{13} \mathrm{C}$ labeling data (Fig. 1), did not appear to be affected in the synGLT-1 KO. Moreover,

${ }^{13} \mathrm{C}$ labeling data from synaptosome experiments suggested that the decreased aspartate amounts in the synGLT-1 KO rather resulted from lower aspartate production than increased utilization. Interestingly, another group using a different conditional neuronal GLT-1 KO mouse reported a 15\% increase in hip- 
pocampal ${ }^{13} \mathrm{C}$ labeling of glutamine from metabolism of ${ }^{13} \mathrm{C}$ glucose. This finding suggests elevated glutamine transfer in the hippocampus of the neuronal GLT-1 KO mice and hence the possibility of regional differences in the role of neuronal GLT-1 (Zhou et al., 2019).

\section{Mitochondrial machinery depends on neuronal GLT-1 expression}

We demonstrate that mitochondria isolated from synGLT-1 KO mice exhibit unchanged oxygen consumption but increased ATP production. Interestingly, in experiments using purified synaptosomes, representing neuronal metabolism, we measured larger responses to stimulation of oxygen consumption by veratridine in the synGLT-1 KO, suggesting an increase in metabolic capacity in the synGLT-1 KO.

EM studies revealed increased density of mitochondria in presynaptic axon terminals of excitatory cortical synapses in synGLT-1 KO mice. These data strongly suggest that expression of GLT-1 in axon terminals contributes to normal synaptic function, and specifically, synaptic mitochondrial function. The increased ATP production/OCR measured in the isolated mitochondria could be interpreted as improved mitochondrial efficiency compensating for reduced influx of glutamate. An underlying mechanism for increased mitochondrial efficiency could involve assembly of ETC complexes into supercomplexes, which have been shown to be associated with increased ETC efficiency in the brain (Lopez-Fabuel et al., 2016). Alternatively, an increase in mitochondrial membrane potential enhancing ATP synthesis might underlie the increase in efficiency in the synGLT-1 KO. Decreased mitochondrial intercristae distance correlates with increased ATP synthase activity (Gomes et al., 2011). Significantly reduced distance between neighboring mitochondrial cristae was observed in the synGLT-1 KO mitochondria, supporting the hypothesis that GLT-1 expressed in neurons directly affects mitochondrial efficiency.

Intriguingly, we observed a larger increase in the occurrence of mitochondria in astrocytic processes $(>100 \%)$ than in axon terminals $(\sim 50 \%)$, in synGLT-1 KO tissue compared with control. These changes could potentially be induced by an imbalance in mitochondrial fusion-fission processes as suggested for the mitochondrial crisis that occurs with aging (Seo et al., 2010). A recent study in mice reported that astrocytes in response to stroke and ATP deficiency can release functional mitochondria that subsequently enter neurons (Hayakawa et al., 2016), a mechanism that may contribute to the findings in the present study.

\section{Neuronal GLT-1 expression is important for synaptic energy metabolism}

Our in vivo metabolic ${ }^{13} \mathrm{C}$ labeling study did not detect any effect of synGLT-1 KO on neuronal or astrocytic metabolism. In contrast, we found reduced glutamate uptake and decreased metabolism of glutamate in cerebral cortical synaptosomes from synGLT-1 KO mice, as well as altered glucose metabolism. It is important to note that, although the in vivo experiments evaluated neuronal metabolism in extracts of cerebral cortex, thereby providing information on overall neuronal metabolism, the experiments performed on isolated synaptosomes dissect out metabolism specifically in axon terminals, where GLT-1 expressed in neurons is primarily localized (Chen et al., 2004).

Our findings extend the well-known role of GLT-1 in mediating glutamate clearance by astrocytes, to include a role in axon terminals to support mitochondrial function. The importance of neuronal GLT-1-mediated glutamate uptake for neuronal energy metabolism is evident from the observed increase in glycolysis in synGLT-1 KO synaptosomes.

It could be speculated that the reduced amounts of aspartate affects the malate-aspartate shuttle activity in the synGLT-1 KO. Malate-aspartate shuttle activity transfers NADH derived from glycolysis into the mitochondria, a process essential for maintenance of oxidative glucose metabolism (McKenna et al., 2006). Another mechanism of reoxidation of cytosolic NADH is through the generation of lactate. This mechanism might be relevant for our observations of increased synaptosomal glycolytic activity and lactate production, which could sustain glycolysis, even with hampered malate-aspartate shuttle activity. We confirm previous studies showing that glutamate indeed does enter the TCA cycle and contributes to energy metabolism in axon terminals (Erecinska et al., 1988; Sonnewald and McKenna, 2002). We suggest here that neuronal GLT-1, expressed in axon terminals, is essential for providing glutamate access to axonal mitochondria.

A role of GLT-1 in axon terminals to provide glutamate for mitochondrial metabolism is in agreement with the relative affinities of the mitochondrial [Aralar, $K_{\mathrm{m}}=0.2 \mathrm{~mm}$ (Monné and Palmieri, 2014) $]$ versus the vesicular $\left[K_{\mathrm{m}}=2 \mathrm{~mm}\right.$ (Anne and Gasnier, 2014)] glutamate transporters. Therefore, transport into mitochondria might be favored over transport into vesicles. However, because intraterminal glutamate concentration is estimated to be in the millimolar range, it is unclear why GLT-1mediated uptake would be necessary to provide glutamate to intraterminal mitochondria. It is possible that GLT-1 has a special function to convey glutamate to mitochondria in neurons, as suggested by previous studies restricted to astrocytes (Genda et al., 2011; Jackson et al., 2014; Robinson and Jackson, 2016).

Bioenergetic failure in synapses has been suggested as playing an important role in the pathogenesis of chronic neurodegenerative diseases, such as Huntington's disease, Parkinson's disease, and Alzheimer's disease (Nunnari and Suomalainen, 2012; Pathak et al., 2013; Devine and Kittler, 2018). Recently, KO of GLT-1 in neurons was shown to produce age-dependent changes in expression of a panel of genes also altered in expression in Huntington's disease (Laprairie et al., 2019). It will be of substantial interest to determine the long-term neuropathological and synaptic consequences of the mitochondrial abnormalities in the neuronal GLT-1 KO reported here, and possible relevance of this model for understanding human neurodegenerative disorders. Our results suggest that GLT-1-mediated uptake in axon terminals provides glutamate for mitochondrial energy metabolism and biosynthetic activities taking place specifically in the presynaptic terminals of excitatory neurons.

\section{References}

Andersen JV, Christensen SK, Nissen JD, Waagepetersen HS (2017a) Improved cerebral energetics and ketone body metabolism in $\mathrm{db} / \mathrm{db}$ mice. J Cereb Blood Flow Metab 37:1137-1147.

Andersen JV, Christensen SK, Aldana BI, Nissen JD, Tanila H, Waagepetersen HS (2017b) Alterations in cerebral cortical glucose and glutamine metabolism precedes amyloid plaques in the APPswe/PSEN1dE9 mouse model of Alzheimer's disease. Neurochem Res 42:1589-1598.

Anne C, Gasnier B (2014) Vesicular neurotransmitter transporters: mechanistic aspects. In: Current topics in membranes (Bevensee MO, ed), pp 149-174. San Diego: Academic.

Azarias G, Perreten H, Lengacher S, Poburko D, Demaurex N, Magistretti PJ, Chatton JY (2011) Glutamate transport decreases mitochondrial pH and modulates oxidative metabolism in astrocytes. J Neurosci 31:3550 3559.

Benjamini Y, Hochberg Y (1995) Controlling the false discovery rate: a 
practical and powerful approach to multiple testing. J R Stat Soc B 57:289-300.

Berger UV, Hediger MA (1998) Comparative analysis of glutamate transporter expression in rat brain using differential double in situ hybridization. Anat Embryol (Berl) 198:13-30.

Bjørås M, Gjesdal O, Erickson JD, Torp R, Levy LM, Ottersen OP, Degree M, Storm-Mathisen J, Seeberg E, Danbolt NC (1996) Cloning and expression of a neuronal rat brain glutamate transporter. Brain Res Mol Brain Res 36:163-168.

Borisova T (2016) Permanent dynamic transporter-mediated turnover of glutamate across the plasma membrane of presynaptic nerve terminals: arguments in favor and against. Rev Neurosci 27:71-81.

Capuani C, Melone M, Tottene A, Bragina L, Crivellaro G, Santello M, Casari G, Conti F, Pietrobon D (2016) Defective glutamate and $\mathrm{K}^{+}$clearance by cortical astrocytes in familial hemiplegic migraine type 2. EMBO Mol Med 8:967-986.

Chatton JY, Magistretti PJ, Barros LF (2016) Sodium signaling and astrocyte energy metabolism. Glia 64:1667-1676.

Chen W, Mahadomrongkul V, Berger UV, Bassan M, DeSilva T, Tanaka K, Irwin N, Aoki C, Rosenberg PA (2004) The glutamate transporter GLT1a is expressed in excitatory axon terminals of mature hippocampal neurons. J Neurosci 24:1136-1148.

Choi SW, Gerencser AA, Nicholls DG (2009) Bioenergetic analysis of isolated cerebrocortical nerve terminals on a microgram scale: spare respiratory capacity and stochastic mitochondrial failure. J Neurochem 109: $1179-1191$.

Danbolt NC (2001) Glutamate uptake. Prog Neurobiol 65:1-105.

Danbolt NC, Furness DN, Zhou Y (2016) Neuronal vs glial glutamate uptake: resolving the conundrum. Neurochem Int 98:29-45.

Devine MJ, Kittler JT (2018) Mitochondria at the neuronal presynapse in health and disease. Nat Rev Neurosci 19:63-80.

de Vivo L, Melone M, Rothstein JD, Conti F (2010) GLT-1 promoter activity in astrocytes and neurons of mouse hippocampus and somatic sensory cortex. Front Neuroanat 3:31.

Erecinska M, Zaleska MM, Nissim I, Nelson D, Dagani F, Yudkoff M (1988) Glucose and synaptosomal glutamate metabolism: studies with $\left[{ }^{15} \mathrm{~N}\right]$ glutamate. J Neurochem 51:892-902.

Fischer KD, Houston AC, Desai RI, Doyle MR, Bergman J, Mian M, Mannix R, Sulzer DL, Choi SJ, Mosharov EV, Hodgson NW, Bechtholt A, Miczek KA, Rosenberg PA (2018) Behavioral phenotyping and dopamine dynamics in mice with conditional deletion of the glutamate transporter GLT-1 in neurons: resistance to the acute locomotor effects of amphetamine. Psychopharmacology (Berl) 235:1371-1387.

Furness DN, Dehnes Y, Akhtar AQ, Rossi DJ, Hamann M, Grutle NJ, Gundersen V, Holmseth S, Lehre KP, Ullensvang K, Wojewodzic M, Zhou Y, Attwell D, Danbolt NC (2008) A quantitative assessment of glutamate uptake into hippocampal synaptic terminals and astrocytes: new insights into a neuronal role for excitatory amino acid transporter 2 (EAAT2). Neuroscience 157:80-94.

Genda EN, Jackson JG, Sheldon AL, Locke SF, Greco TM, O'Donnell JC, Spruce LA, Xiao R, Guo W, Putt M, Seeholzer S, Ischiropoulos H, Robinson MB (2011) Co-compartmentalization of the astroglial glutamate transporter, GLT-1, with glycolytic enzymes and mitochondria. J Neurosci 31:18275-18288.

Gomes LC, Di Benedetto G, Scorrano L (2011) Essential amino acids and glutamine regulate induction of mitochondrial elongation during autophagy. Cell Cycle 10:2635-2639.

Grewer C, Gameiro A, Zhang Z, Tao Z, Braams S, Rauen T (2008) Glutamate forward and reverse transport: from molecular mechanism to transporter-mediated release after ischemia. IUBMB Life 60:609-619.

Håberg A, Qu H, Haraldseth O, Unsgård G, Sonnewald U (1998) In vivo injection of $\left[1-{ }^{13} \mathrm{C}\right]$ glucose and $\left[1,2-{ }^{13} \mathrm{C}\right]$ acetate combined with ex vivo ${ }^{13} \mathrm{C}$ nuclear magnetic resonance spectroscopy: a novel approach to the study of middle cerebral artery occlusion in the rat. J Cereb Blood Flow Metab 18:1223-1232.

Harno E, Cottrell EC, White A (2013) Metabolic pitfalls of CNS Cre-based technology. Cell Metab 18:21-28.

Hassel B, Sonnewald U, Fonnum F (1995) Glial-neuronal interactions as studied by cerebral metabolism of $\left[2-{ }^{13} \mathrm{C}\right]$ acetate and $\left[1-{ }^{13} \mathrm{C}\right]$ glucose: an ex vivo ${ }^{13} \mathrm{C}$ NMR spectroscopic study. J Neurochem 64:2773-2782.

Hayakawa K, Esposito E, Wang X, Terasaki Y, Liu Y, Xing C, Ji X, Lo EH
(2016) Transfer of mitochondria from astrocytes to neurons after stroke. Nature 535:551-555.

Hohnholt MC, Andersen VH, Bak LK, Waagepetersen HS (2017) Glucose, lactate and glutamine but not glutamate support depolarization-induced increased respiration in isolated nerve terminals. Neurochem Res 42:191-201.

Hohnholt MC, Andersen VH, Andersen JV, Christensen SK, Karaca M, Maechler P, Waagepetersen HS (2018) Glutamate dehydrogenase is essential to sustain neuronal oxidative energy metabolism during stimulation. J Cereb Blood Flow Metab 38:1754-1768.

$\mathrm{Hu} \mathrm{H}$, Cavendish JZ, Agmon A (2013) Not all that glitters is gold: off-target recombination in the somatostatin-IRES-Cre mouse line labels a subset of fast-spiking interneurons. Front Neural Circuits 7:195.

Jackson JG, O’Donnell JC, Takano H, Coulter DA, Robinson MB (2014) Neuronal activity and glutamate uptake decrease mitochondrial mobility in astrocytes and position mitochondria near glutamate transporters. J Neurosci 34:1613-1624.

Kam K, Nicoll R (2007) Excitatory synaptic transmission persists independently of the glutamate-glutamine cycle. J Neurosci 27:9192-9200.

Kanai Y, Hediger MA (1992) Primary structure and functional characterization of a high-affinity glutamate transporter. Nature 360:467-471.

Laprairie RB, Petr GT, Sun Y, Fischer KD, Denovan-Wright EM, Rosenberg PA (2019) Huntington's disease pattern of transcriptional dysregulation in the absence of mutant huntingtin is produced by knockout of neuronal GLT-1. Neurochem Int 123:85-94.

Le Belle JE, Harris NG, Williams SR, Bhakoo KK (2002) A comparison of cell and tissue extraction techniques using high-resolution 1H-NMR spectroscopy. NMR Biomed 15:37-44.

Lee JY, Ristow M, Lin X, White MF, Magnuson MA, Hennighausen L (2006) RIP-Cre revisited, evidence for impairments of pancreatic beta-cell function. J Biol Chem 281:2649-2653.

Lopez-Fabuel I, Le Douce J, Logan A, James AM, Bonvento G, Murphy MP, Almeida A, Bolaños JP (2016) Complex I assembly into supercomplexes determines differential mitochondrial ROS production in neurons and astrocytes. Proc Natl Acad Sci U S A 113:13063-13068.

Lundgaard I, Li B, Xie L, Kang H, Sanggaard S, Haswell JD, Sun W, Goldman S, Blekot S, Nielsen M, Takano T, Deane R, Nedergaard M (2015) Direct neuronal glucose uptake heralds activity-dependent increases in cerebral metabolism. Nat Commun 6:6807.

McKenna MC (2013) Glutamate pays its own way in astrocytes. Front Endocrinol (Lausanne) 4:191.

McKenna MC, Waagepetersen HS, Schousboe A, Sonnewald U (2006) Neuronal and astrocytic shuttle mechanisms for cytosolic-mitochondrial transfer of reducing equivalents: current evidence and pharmacological tools. Biochem Pharmacol 71:399-407.

Melone M, Bellesi M, Conti F (2009) Synaptic localization of GLT-1a in the rat somatic sensory cortex. Glia 57:108-117.

Melone M, Bellesi M, Ducati A, Iacoangeli M, Conti F (2011) Cellular and synaptic localization of EAAT2a in human cerebral cortex. Front Neuroanat 4:151.

Moffett JR, Ross B, Arun P, Madhavarao CN, Namboodiri AM (2007) $N$-Acetylaspartate in the CNS: from neurodiagnostics to neurobiology. Prog Neurobiol 81:89-131.

Monné M, Palmieri F (2014) Antiporters of the mitochondrial carrier family. In: Current topics in membranes (Bevensee MO, ed), pp 289-320. San Diego: Academic.

Morken TS, Brekke E, Håberg A, Widerøe M, Brubakk AM, Sonnewald U (2014) Altered astrocyte-neuronal interactions after hypoxia-ischemia in the neonatal brain in female and male rats. Stroke 45:2777-2785.

Nissen JD, Pajecka K, Stridh MH, Skytt DM, Waagepetersen HS (2015) Dysfunctional TCA-cycle metabolism in glutamate dehydrogenase deficient astrocytes. Glia 63:2313-2326.

Nunnari J, Suomalainen A (2012) Mitochondria: in sickness and in health. Cell 148:1145-1159.

Olstad E, Olsen GM, Qu H, Sonnewald U (2007) Pyruvate recycling in cultured neurons from cerebellum. J Neurosci Res 85:3318-3325.

Ottersen OP, Storm-Mathisen J (1984) Glutamate- and GABA-containing neurons in the mouse and rat brain, as demonstrated with a new immunocytochemical technique. J Comp Neurol 229:374-392.

Ottersen OP, Storm-Mathisen J (1985) Different neuronal localization of aspartate-like and glutamate-like immunoreactivities in the hippocam- 
pus of rat, guinea-pig and Senegalese baboon (Papio papio), with a note on the distribution of gamma-aminobutyrate. Neuroscience 16:589-606.

Ottersen OP, Laake JH, Reichelt W, Haug FM, Torp R (1996) Ischemic disruption of glutamate homeostasis in brain: quantitative immunocytochemical analyses. J Chem Neuroanat 12:1-14.

Palm W, Thompson CB (2017) Nutrient acquisition strategies of mammalian cells. Nature 546:234-242.

Pardo B, Rodrigues TB, Contreras L, Garzón M, Llorente-Folch I, Kobayashi K, Saheki T, Cerdan S, Satrústegui J (2011) Brain glutamine synthesis requires neuronal-born aspartate as amino donor for glial glutamate formation. J Cereb Blood Flow Metab 31:90-101.

Pathak D, Berthet A, Nakamura K (2013) Energy failure: does it contribute to neurodegeneration? Ann Neurol 74:506-516.

Petr GT, Schultheis LA, Hussey KC, Sun Y, Dubinsky JM, Aoki C, Rosenberg PA (2013) Decreased expression of GLT-1 in the R6/2 model of Huntington's disease does not worsen disease progression. Eur J Neurosci 38:2477-2490.

Petr GT, Sun Y, Frederick NM, Zhou Y, Dhamne SC, Hameed MQ, Miranda C, Bedoya EA, Fischer KD, Armsen W, Wang J, Danbolt NC, Rotenberg A, Aoki CJ, Rosenberg PA (2015) Conditional deletion of the glutamate transporter GLT-1 reveals that astrocytic GLT-1 protects against fatal epilepsy while neuronal GLT-1 contributes significantly to glutamate uptake into synaptosomes. J Neurosci 35:5187-5201.

Pines G, Danbolt NC, Bjorås M, Zhang Y, Bendahan A, Eide L, Koepsell H, Storm-Mathisen J, Seeberg E, Kanner BI (1992) Cloning and expression of a rat brain L-glutamate transporter. Nature 360:464-467.

Qu H, Håberg A, Haraldseth O, Unsgård G, Sonnewald U (2000) ${ }^{13} \mathrm{C} \mathrm{MR}$ spectroscopy study of lactate as substrate for rat brain. Dev Neurosci 22:429-436.

Rimmele TS, Rosenberg PA (2016) GLT-1: the elusive presynaptic glutamate transporter. Neurochem Int 98:19-28.

Robinson MB, Jackson JG (2016) Astroglial glutamate transporters coordinate excitatory signaling and brain energetics. Neurochem Int 98:56-71.

Rothstein JD, Dykes-Hoberg M, Pardo CA, Bristol LA, Jin L, Kuncl RW, Kanai Y, Hediger MA, Wang Y, Schielke JP, Welty DF (1996) Knockout of glutamate transporters reveals a major role for astroglial transport in excitotoxicity and clearance of glutamate. Neuron 16:675-686.

Schmidt-Supprian M, Rajewsky K (2007) Vagaries of conditional gene targeting. Nat Immunol 8:665-668.

Seo AY, Joseph AM, Dutta D, Hwang JC, Aris JP, Leeuwenburgh C (2010) New insights into the role of mitochondria in aging: mitochondrial dynamics and more. J Cell Sci 123:2533-2542.

Sonnewald U (2014) Glutamate synthesis has to be matched by its degradation: where do all the carbons go? J Neurochem 131:399-406.

Sonnewald U, McKenna M (2002) Metabolic compartmentation in cortical synaptosomes: influence of glucose and preferential incorporation of endogenous glutamate into GABA. Neurochem Res 27:43-50.

Sonnewald U, Westergaard N, Schousboe A, Svendsen JS, Unsgård G, Petersen SB (1993) Direct demonstration by [13C]NMR spectroscopy that glutamine from astrocytes is a precursor for GABA synthesis in neurons. Neurochem Int 22:19-29.
Storm-Mathisen J, Danbolt NC, Rothe F, Torp R, Zhang N, Aas JE, Kanner BI, Langmoen I, Ottersen OP (1992) Ultrastructural immunocytochemical observations on the localization, metabolism and transport of glutamate in normal and ischemic brain tissue. Prog Brain Res 94:225-241.

Stuber GD, Stamatakis AM, Kantak PA (2015) Considerations when using Cre-driver rodent lines for studying ventral tegmental area circuitry. Neuron 85:439-445.

Tanaka K, Watase K, Manabe T, Yamada K, Watanabe M, Takahashi K, Iwama H, Nishikawa T, Ichihara N, Kikuchi T, Okuyama S, Kawashima N, Hori S, Takimoto M, Wada K (1997) Epilepsy and exacerbation of brain injury in mice lacking the glutamate transporter GLT-1. Science 276:1699-1702.

Tani H, Dulla CG, Farzampour Z, Taylor-Weiner A, Huguenard JR, Reimer RJ (2014) A local glutamate-glutamine cycle sustains synaptic excitatory transmitter release. Neuron 81:888-900.

Taugher RJ, Lu Y, Fan R, Ghobbeh A, Kreple CJ, Faraci FM, Wemmie JA (2017) ASIC1A in neurons is critical for fear-related behaviors. Genes Brain Behav 16:745-755.

Torp R, Danbolt NC, Babaie E, Bjorås M, Seeberg E, Storm-Mathisen J, Ottersen OP (1994) Differential expression of two glial glutamate transporters in the rat brain: an in situ hybridization study. Eur J Neurosci 6:936-942.

Torp R, Hoover F, Danbolt NC, Storm-Mathisen J, Ottersen OP (1997) Differential distribution of the glutamate transporters GLT1 and rEAAC1 in rat cerebral cortex and thalamus: an in situ hybridization analysis. Anat Embryol (Berl) 195:317-326.

Venneti S, Thompson CB (2017) Metabolic reprogramming in brain tumors. Annu Rev Pathol 12:515-545.

Waagepetersen HS, Qu H, Sonnewald U, Shimamoto K, Schousboe A (2005) Role of glutamine and neuronal glutamate uptake in glutamate homeostasis and synthesis during vesicular release in cultured glutamatergic neurons. Neurochem Int 47:92-102.

Walls AB, Bak LK, Sonnewald U, Schousboe A, Waagepetersen HS (2014) Metabolic mapping of astrocytes and neurons in culture using stable isotopes and gas chromatography-mass spectrometry (GC-MS). In: Brain energy metabolism. Neuromethods (Hirrlinger J, Waagepetersen HS eds), Vol 90. Humana Press, New York.

Walls AB, Waagepetersen HS, Bak LK, Schousboe A, Sonnewald U (2015) The glutamine-glutamate/GABA cycle: function, regional differences in glutamate and GABA production and effects of interference with GABA metabolism. Neurochem Res 40:402-409.

Watzke N, Grewer C (2001) The anion conductance of the glutamate transporter EAAC1 depends on the direction of glutamate transport. FEBS Lett 503:121-125.

Zhang J, Pavlova NN, Thompson CB (2017) Cancer cell metabolism: the essential role of the nonessential amino acid, glutamine. EMBO J 36:1302-1315.

Zhou Y, Hassel B, Eid T, Danbolt NC (2019) Axon-terminals expressing EAAT2 (GLT-1; Slcla2) are common in the forebrain and not limited to the hippocampus. Neurochem Int 123:101-113. 